Renata Ribeiro de Mendonça Pilan

\title{
Prevalência da rinossinusite crônica através de inquéritos domiciliares na cidade de São Paulo
}

Tese apresentada à Faculdade de Medicina da Universidade de São Paulo para obtenção do título de Doutor em Ciências

Programa de Otorrinolaringologia

Orientador: Prof. Dr. Richard Louis Voegels

São Paulo

2014 


\section{Dados Internacionais de Catalogação na Publicação (CIP)}

Preparada pela Biblioteca da

Faculdade de Medicina da Universidade de São Paulo

Creprodução autorizada pelo autor

Pilan, Renata Ribeiro de Mendonça

Prevalência da rinossinusite crônica através de inquéritos domiciliares na cidade de São Paulo / Renata Ribeiro de Mendonça Pilan. --- São Paulo, 2014 Tese(doutorado)--Faculdade de Medicina da Universidade de São Paulo.

Programa de Otorrinolaringologia.

Orientador: Richard Louis Voegels.

Descritores: 1.Sinusite 2.Prevalência 3.Sinusite/epidemiologia 4.Doença crônica 5.Epidemiologia 6.Brasil/epidemiologia 7.Inquéritos epidemiológicos 8.Análise por conglomerados 9.Hábito de fumar/epidemiologia 10.Políticas públicas de saúde 11.Coleta de dados

USP/FM/DBD-082/14 
"Todas as grandes coisas do mundo começam nas pequenas (...). Uma jornada de mil milhas começa com o pedaço de chão debaixo do pé"

Lao-Tsé 
Dedicatória

Aos meus pais, Eduardo e Regina, por todo o amor e dedicação.

Ao meu grande amor, Luis, pelo apoio e companheirismo, e aos meus filhos Rafael e Gustavo, pela alegria que trouxeram para nossas vidas. 


\section{AGRADECIMENTOS}

Ao Prof. Dr. Richard Louis Voegels, Diretor de Rinologia do Departamento de Otorrinolaringologia do Hospital das Clínicas da FMUSP e orientador desta tese, serei eternamente grata pelo acolhimento no Hospital das Clínicas e por todos os incentivos e oportunidades oferecidos. Obrigada pela confiança e amizade e esteja certo que tenho muito orgulho de fazer parte do Grupo de Rinologia, principalmente pela admiração e respeito que tenho por você.

Ao Prof. Dr. Ricardo Ferreira Bento, Professor Titular da Disciplina de Otorrinolaringologia da FMUSP, pela oportunidade de ingressar na nesta instituição e aprimorar minha formação profissional.

Ao Prof. Dr. Luis Ubirajara Sennes, Coordenador da PósGraduação, pelo incentivo nas atividades acadêmicas e pelo exemplo de profissionalismo.

Ao Prof. Dr. Ossamu Butugan, pela generosidade, sabedoria e humildade. Em nossas visitas e reuniões recebi valiosos ensinamentos que não estão escritos em livro algum.

Ao Prof Dr. Julio Cesar Rodrigues Pereira, Professor Associado da Universidade de São Paulo, Doutor em Epidemiologia pela Faculdade de Saúde Pública, cuja orientação no desenho deste estudo foi fundamental para que eu desse os primeiros passos nesta jornada epidemiológica.

Às grandes amigas de longa data e companheiras de todas as horas, Dra. Tatiana Abdo, Dra. Renata Lopes Mori e Dra. Roberta Garcia, obrigada pela amizade e pelo apoio.

Ao Dr. Thiago Bezerra, exímio pesquisador, agradeço muito as sugestões e revisões. Sua participação foi extremamente enriquecedora neste projeto. 
Ao Dr. Fabio Pinna e Dr. Rui Imamura, pelas diversas reuniões para discussão de metodologia e estatística, além de revisão do texto. Suas sugestões e críticas engrandeceram o projeto.

À equipe formada pelas estatísticas Cecília Porto, Maria Mercedes e Regina Bernal e às coordenadoras do trabalho de campo Mariângela e Margaret, à todos entrevistadores, pela competência, interesse e dedicação ao projeto.

A Prof. Dra. Priscila Bogar e ao Dr. Fernando Veiga, pelo carinho, incentivo e ensinamentos que recebi em minha formação em Otorrinolaringologia. Minha vida profissional tomaria outro rumo se não cruzasse com vocês neste caminho.

Aos Assistentes e amigos da Disciplina de Otorrinolaringologia da FMABC, tão importantes na minha formação e que não mediram esforços para transmitir todo conhecimento. Muito me influenciaram na graduação $\mathbf{D r}$. Carlos Anadão e Dr. Carlos Eduardo Rezende, e na residência médica os Drs. Marcos Antunes, Rodrigo O. Santos, Ivan P. Uvo e Ronaldo Frizarinni, entre outros, também muito queridos. E especialmente ao casal Dr. Leonardo Haddad e Dra. Fernanda Martinho Haddad, que me impulsionaram e me guiaram em importantes escolhas profissionais.

Ao querido Grupo de Rinologia, formado por Assistentes, Fellowships e Pós-graduandos, colegas que se tornaram amigos, Drs. Fabio, Tatiana, Marco Antônio, Nelson, Diego, Flavia, Dani, Aline, Maria, Marco Aurélio, Ana, Thiago e a todos os outros que por lá passaram e que sempre demonstraram comprometimento e dedicação.

Aos membros participantes da minha banca de qualificação, Prof. Dr. Luis Ubirajara Sennes, Dra. Tatiana Abdo, Dr. Michel B. Cahali, Dr. João Mello Jr. e Dr. Rui Imamura pelas sugestões pertinentes que contribuíram para a melhoria desta tese. 
À Profa. Barbara Rzyski, pela simpatia, empenho e profissionalismo no auxílio para a revisão gramatical e ortográfica e formatação deste trabalho.

Às secretárias Márcia, Kátia, Luci sempre prestativas e atenciosas e, especialmente, à Marilede, pelo carinho, paciência e valiosa ajuda.

Aos queridos Residentes e Ex-residentes da FMUSP e FMABC, nestes dez anos de preceptoria, durante os quais confirmo que ensinar é a melhor forma de aprender. É um prazer imenso poder assistir e participar da formação de cada um de vocês.

À minha querida família, meus pais Eduardo e Regina, minha irmã Camila, minha saudosa Vovó Yedda, meus sogros Carmen e José Antônio, e principalmente ao meu marido Luis e aos pequenos Rafael e Gustavo, que compreenderam meus momentos de ausência e me deram toda a estrutura e incentivo para concretizar este sonho.

Às secretárias Márcia, Kátia, Luci sempre prestativas e atenciosas e, especialmente, à Marilede, pelo carinho, paciência e valiosa ajuda.

Aos queridos Residentes e Ex-residentes da FMUSP e FMABC, nestes dez anos de preceptoria, durante os quais confirmo que ensinar é a melhor forma de aprender. É um prazer imenso poder assistir e participar da formação de cada um de vocês.

E, finalmente, aos meus avós, os médicos Luis Edmundo Ribeiro de Mendonça e Jalles Martins Salgueiro, sobre os quais escutei muitas histórias do amor e dedicação à Medicina, seja pelos estudos diários, na realização de consultas domiciliares ou acolhendo os doentes em sua própria casa. Obrigada por me transmitirem o desejo do cuidado ao próximo e a vontade de estudar e ensinar, e desta forma sinto que uma parte de vocês ainda vive em mim. 


\section{AGRADECIMENTOS ESPECIAIS}

À Associação Brasileira de Otorrinolaringologia e Cirurgia Cérvico Facial (ABORLCCF) pelo reconhecimento da importância do estudo epidemiológico e apoio a este projeto.

Ao Conselho Nacional de Desenvolvimento Científico e Tecnológico (CNPq) pela concessão da bolsa de doutorado.

À Fundação do Amparo à Pesquisa do Estado de São Paulo (FAPESP), pela concessão do auxílio à pesquisa e o apoio financeiro para a realização deste projeto. 


\section{Normalização adotada}

Esta dissertação ou tese está de acordo com as seguintes normas, em vigor no momento desta publicação:

Referências: adaptado de International Committee of Medical Journals Editors (Vancouver).

Universidade de São Paulo. Faculdade de Medicina. Divisão de Biblioteca e Documentação. Guia de apresentação de dissertações, teses e monografias. Elaborado por Anneliese Carneiro da Cunha, Maria Julia de A. L. Freddi, Maria F. Crestana, Marinalva de Souza Aragão, Suely Campos Cardoso, Valéria Vilhena. 3a ed. São Paulo: Divisão de Biblioteca e Documentação; 2011.

Abreviaturas dos títulos dos periódicos de acordo com List of Journals Indexed in Index Medicus. 


\section{SUMÁRIO}

Lista de abreviaturas

Lista de siglas

Lista de símbolos

Lista de quadros e figuras

Lista de tabelas

Resumo

Abstract

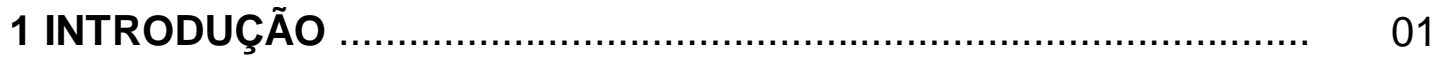

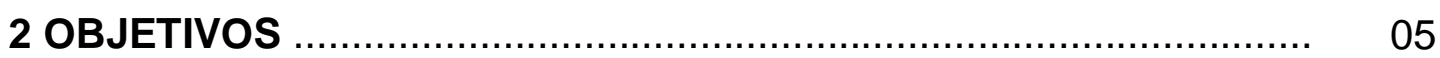

2.1. Objetivo principal ........................................................... 06

2.2. Objetivos secundários .............................................................. 06

3 REVISÃO DA LITERATURA ............................................... 07

3.1 Diagnóstico ....................................................................... 08

3.2 Epidemiologia .............................................................. 11

3.3 Validação do critério epidemiológico de RSC ............................. 17

3.4 RSC e Asma ................................................................ 19

3.5 RSC e Rinite ................................................................... 21

3.6 RSC e Tabagismo ............................................................. 23

3.7 RSC e Fatores socioeconômicos ............................................... 25

4 MÉTODO................................................................................. 27

4.1 Aspecto ético................................................................ 28

4.2 Auxílio pesquisa.............................................................. 28

4.3 Tipo de estudo............................................................... 28

4.4 Plano de amostragem - Cálculo do tamanho da amostra ............... 29

4.5 Sorteio dos setores censitários ............................................... 33

4.6 Sorteio dos domicílios .......................................................... 36

4.7 Processo de amostragem - Adequações na fase de campo ........... 37

4.8 Preparação e coleta de dados nos domicílios ............................... 40

4.9 Definição das variáveis do estudo ............................................... 43 
4.10 Análise estatística .............................................................. 45

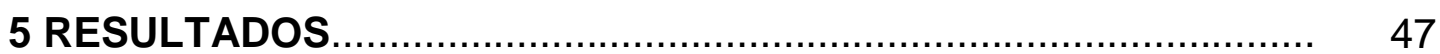

5.1 Entrevistas realizadas e taxas de resposta ................................ 48

5.2 Dados da amostra ................................................................... 49

6 DISCUSSÃO ….......................................................... 55

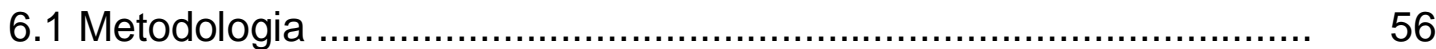

6.2 Critério diagnóstico ............................................................... 58

6.3 Taxa de resposta ........................................................... 60

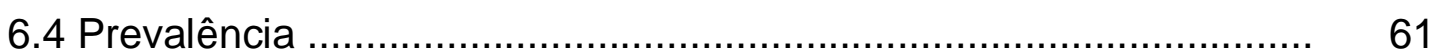

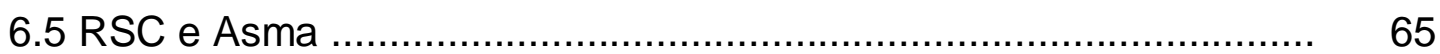

6.6 RSC e Rinite ...................................................................... 67

6.7 RSC e Tabagismo ................................................................ 69

6.8 RSC e Fatores socioeconômicos ............................................... 71

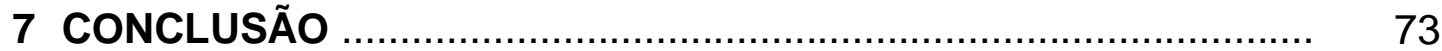

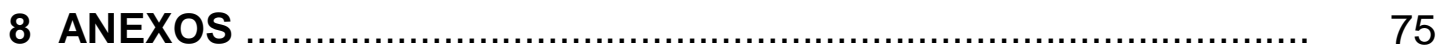

Anexo A - Setores sorteados para o levantamento ........................... 76

Anexo B - Questionários ........................................................... 78

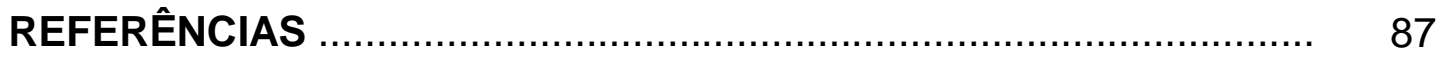

\section{APÊNDICES}

Apêndice 1 - Carta da Comissão de Ética

Apêndice 2 - Termo de Consentimento Livre e Esclarecido 


\section{LISTA DE ABREVIATURAS}

$\begin{array}{ll}\text { ARIA } & \text { Allergic Rhinitis and its Impact on Asthma } \\ \text { CID } & \text { Código Internacional de Doenças } \\ \text { DPOC } & \text { Doença Pulmonar Obstrutiva Crônica } \\ \text { et al. } & \text { e colaboradores } \\ \text { EP }^{3} \text { OS } & \text { European Position Paper on Rhinosinusitis and Nasal Polyps } \\ \text { GA }^{2} \text { LEN } & \text { Global Allergy and Asthma Network of Excellence } \\ \text { IC } & \text { Intervalo de Confiança } \\ \text { IgE } & \text { Imunoglobulina E } \\ \text { OLS } & \text { Ordinary least squares (quadrados mínimos ordinários) } \\ \text { OR } & \text { Odds Ratio }\end{array}$

RA Rinite Alérgica

RAST Radio Allergo Sorbent Test

RNA Rinite Não Alérgica

RS Rinossinusite

RSC Rinossinusite Crônica

SF-36 Medical Outcomes Study Short Form 36 Health Survey

SAHP Sinus and Allergy Health Partnership

SIDRA Sistema IBGE de Recuperação Automática

SNOT-20 Sinonasal Outcome Test-20

TC Tomografia Computadorizada

vs. versus 


\section{LISTA DE SIGLAS}

ABORLCCF Associação Brasileira de Otorrinolaringologia e Cirurgia Cérvico Facial

CAPPesq Comissão de Ética para Análises de Projetos de Pesquisa

CDC Center for Disease Control and Prevention

EUA Estados Unidos da América

FAPESP Fundação de Amparo à Pesquisa do Estado de São Paulo

HCFMUSP Hospital das Clínicas da Faculdade de Medicina da

Universidade de São Paulo

IBGE Instituto Brasileiro de Geografia e Estatística

NCHS National Center for Health Statistics

NHIS National Health Interview Survey

USP Universidade de São Paulo 


\section{LISTA DE SÍMBOLOS}

$\begin{array}{ll}= & \text { igual a } \\ > & \text { maior que } \\ \geq & \text { maior ou igual } \\ < & \text { menor que } \\ \leq & \text { menor ou igual } \\ \% & \text { porcento }\end{array}$




\section{LISTA DE QUADROS E FIGURAS}

Quadro 1 Definição epidemiológica de Rinossinusite Crônica ........ 11

Figura 1 No detalhe: distrito de Pinheiros e seus censitários ....... 34 


\section{LISTA DE TABELAS}

Tabela 1 Sintomas maiores e menores para o diagnóstico clínico de rinossinusite ............................................................ 9

Tabela 2 Prevalência de RS em adultos nos Estados Unidos,

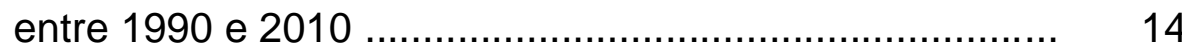

Tabela 3 População residente no Município de São Paulo, segundo a idade de acordo com o Censo Demográfico do ano 2000

Tabela 4 Tamanhos de amostras proporcionais, planejadas e pesos, segundo idade

Tabela 5 Razão pessoas / domicílios e quantidade de domicílios a serem visitados, segundo idade

Tabela 6 Setores censitários do Censo do IBGE (2000), classificados por situação e tipo

Tabela 7 Pesos segundo estação e faixa etária

Tabela 8 Quantidade de entrevistas previstas na amostra e de entrevistas realizadas, São Paulo, SP, 2010-2011

Tabela 9 Distribuição da amostra e prevalência da rinossinusite crônica em pessoas com 12 anos ou mais, segundo variáveis sociodemográficas, condições de saúde e estado tabágico, São Paulo, SP, 2010-2011

Tabela 10 Prevalência de rinossinusite crônica (segundo critério epidemiológico $E P^{3} \mathrm{OS}$ ) x prevalência de rinossinusite autorreferida, em pessoas com 12 anos ou mais, São Paulo, SP, 2010-2011

Tabela 11 Razão de chances (odds ratio) de rinossinusite crônica, segundo características sociodemográficas e condições de saúde, São Paulo, SP, 2010-2011 
Tabela 12 Razão de chances (odds ratio) de rinossinusite crônica, segundo estado tabágico, São Paulo, SP, 2010-2011 ....

Tabela 13 Plano de amostragem, critério diagnóstico e taxa de resposta entre os estudos analisados ........................... 57

Tabela 14 Características da amostra e prevalência de RSC entre os trabalhos analisados

Tabela 15 Razão de chances (odds ratio) de rinossinusite crônica e presença de asma, entre os estudos analisados

Tabela 16 Razão de chances (odds ratio) de rinossinusite crônica e presença de rinite, entre os estudos analisados

Tabela 17 Razão de chances (odds ratio) de rinossinusite crônica e estado tabágico ente os estudos analisados

Tabela 18 Razão de chances (odds ratio) de rinossinusite crônica e características econômicas entre os estudos analisados 


\section{RESUMO}

Pilan RRM. Prevalência da rinossinusite crônica através de inquéritos domiciliares na cidade de São Paulo [tese]. São Paulo: Faculdade de Medicina, Universidade de São Paulo; 2014.

INTRODUÇÃO: A rinossinusite crônica (RSC) é uma doença comum na população, com documentada repercussão na qualidade de vida e com alto custo direto em saúde pública que engloba consultas médicas, exames complementares e radiológicos, internações hospitalares, cirurgias e tratamento medicamentoso. Apresenta também custos indiretos como diminuição da produtividade no trabalho e absenteísmo. Os dados epidemiológicos sobre rinossinusite crônica são escassos; e as definições de rinossinusite crônica estabelecidas, as metodologias das pesquisas e as taxas de respostas diferem muito entre si. A pesquisa epidemiológica da RSC é importante para avaliar sua distribuição, analisar seus fatores de risco e fornecer dados para promoção de políticas de saúde pública, entretanto não existem dados epidemiológicos sobre a prevalência desta doença em nossa população. MÉTODO: Foi realizado um inquérito transversal de base populacional (survey) com plano de amostragem complexo realizado em dois estágios: setor censitário e domicílio. Entrevistas foram conduzidas pessoalmente, através de entrevistadores treinados, em 2003 indivíduos com idade de 12 anos ou mais, residentes da cidade de São Paulo. O questionário incluiu o diagnóstico de rinossinusite crônica segundo os critérios epidemiológicos estabelecido pelo $\mathrm{EP}^{3} \mathrm{OS}$. Dados demográficos, diagnóstico médico autorreferido de doenças respiratórias (asma, sinusite, rinite), tabagismo, renda familiar, nível educacional e características do domicílio também foram incluídas. RESULTADOS: A taxa de resposta total foi de $87,8 \%$. A idade média foi de 39,8 anos ( $D P=21,12-92$ ), $45,33 \%$ do sexo masculino. A prevalência da rinossinusite crônica na cidade de São Paulo foi de 5,51\% (IC 95\%=3,99-7,58). Não existiu uma diferença estatisticamente significativa na prevalência segundo o sexo. Foi encontrada uma associação estatisticamente significativa do diagnóstico de RSC com o diagnóstico de asma $(\mathrm{OR}=3.88)$, de rinite $(\mathrm{OR}=5,02)$ e com o subgrupo de baixa renda $(\mathrm{OR}=2,28)$ As prevalências de $\mathrm{RSC}$ segundo o estado tabágico $(p=0,43)$, consumo tabágico em anos.maço $(p=0,26)$ e tabagismo passivo intradomiciliar $(p=0,18)$ não apresentaram uma diferença estatisticamente significativa. CONCLUSÃO: A prevalência estimada de RSC na população da cidade de São Paulo é de 5,51\% (aproximadamente 500.000 indivíduos). Foi encontrada associação com rinite, asma e com o subgrupo de baixa renda. Não houve associação com tabagismo.

DESCRITORES: Sinusite; Prevalência; Sinusite/epidemiologia; Doença crônica; Epidemiologia; Brasil/epidemiologia; Inquéritos epidemiológicos; Análise por conglomerados; Hábito de fumar/epidemiologia; Políticas públicas de saúde; Coleta de dados. 


\begin{abstract}
Pilan RRM. Prevalence of chronic rhinosinusitis by household surveys in the city of São Paulo [thesis]. São Paulo: "Faculdade de Medicina, Universidade de São Paulo"; 2014.

INTRODUCTION: Chronic rhinosinusitis (CRS) is a common disease with proven repercussions on quality of life and a high burden of direct costs to public health, which included physician visits, laboratory tests and medical imaging, hospital admissions, surgical intervention, and medical treatment. It also carries indirect costs, such as decreased productivity in the workplace and absenteeism. Epidemiological data on CRS are scarce, and the established definitions of CRS, study methods, and response rates vary widely. Epidemiological research into CRS is important to assess its distribution, analyze its risk factors, and provide data to subsidize public health policies; however, there are no epidemiological data on the prevalence of this disease in our population. METHOD: This was a cross-sectional populationbased survey with a complex cluster sampling plan carried out in two stages: census sector and household. Interviews of 2,003 individuals, aged 12 years or older and living in the city of São Paulo, were conducted face-to-face by trained investigators. The questionnaire included diagnosis of CRS according to the epidemiological criteria established by EP3OS. Demographic data, a self-reported history of physician-diagnosed respiratory diseases (asthma, sinusitis, rhinitis), smoking, family income, educational attainment, and household characteristics were also included. RESULTS: The overall response rate was $87.8 \%$. The mean age was 39.8 years $(S D=21$ years; range $=12-92$ ), and $45.33 \%$ were male. The prevalence of CRS in the city of São Paulo was $5.51 \%(95 \% \mathrm{Cl}=3.99-7.58)$. There was no statistically significant difference in prevalence between the sexes. Statistically significant associations were found between diagnosis of CRS and diagnosis of asthma $(\mathrm{OR}=3.88)$, of rhinitis $(\mathrm{OR}=5.02)$, and belonging to the low-income subgroup $(\mathrm{OR}=2.28)$ The prevalences of $\mathrm{CRS}$ according to smoking status $(\mathrm{p}=0.43)$, tobacco intake in pack years $(p=0.26)$ or exposure to passive smoking in the household $(p=0.18)$ did not exhibit a statistically significant difference. CONCLUSION: The estimated population-wide prevalence of CRS in the city of São Paulo is $5.51 \%$ (approximately 500,000 individuals). Associations were found with rhinitis, asthma, and low income. There was no association with smoking.
\end{abstract}

DESCRIPTORS: Sinusitis; Prevalence; Sinusitis/epidemiology; Chronic disease; Epidemiology; Brazil/epidemiology; Health surveys; Cluster analysis; Smoking/epidemiology; Health public policy; Data collection. 
1 INTRODUÇÃO 


\section{INTRODUÇÃO}

A rinossinusite crônica (RSC) é uma doença comum na população e as pesquisas sobre seus dados epidemiológicos são importantes para avaliar sua distribuição, analisar os fatores de risco e promover políticas públicas de saúde.

Esta doença apresenta um custo direto alto em saúde pública que engloba consultas médicas, exames complementares e radiológicos, internações hospitalares, cirurgias e tratamento medicamentoso. Apresenta, também, custos indiretos como diminuição da produtividade no trabalho (presenteísmo) e absenteísmo ${ }^{(1-4)}$. Nos Estados Unidos (EUA), o gasto estimado dos pacientes com este diagnóstico é de US\$8,6 bilhões por ano ${ }^{(5)}$, destes, US $\$ 150$ milhões são com o uso de antibióticos ${ }^{(6)}$.

Os questionários sobre avaliação da qualidade de vida dos tipos global e doença-específica mostram o impacto da RSC na qualidade de vida dos pacientes ${ }^{(7-9)}$. O questionário de qualidade de vida global SF-36 (Medical Outcomes Study Short Form 36 Health Survey) é um instrumento que afere essa qualidade por meio de 36 questões que abordam oito domínios do indivíduo: capacidade funcional, aspectos físicos, dor, estado geral da saúde, vitalidade, aspectos sociais, aspectos emocionais e saúde mental ${ }^{(10)}$. Em 2001, Durr et al. ${ }^{(7)}$ avaliaram a população com rinossinusite da crônica da cidade de Quebec aplicando o questionário SF-36. Houve 
redução estatisticamente significativa do escore em sete dos oito domínios (exceto capacidade funcional), em comparação com indivíduos saudáveis. No estudo de Glicklich et al. ${ }^{(9)}$ (1995) os pacientes com RSC apresentaram uma morbidade maior do que doentes com insuficiência cardíaca congestiva, angina, doença pulmonar obstrutiva crônica e dor lombar, nos domínios "Aspectos Sociais" e "Dor".

Nos poucos estudos epidemiológicos disponíveis, as definições de rinossinusite crônica estabelecidas, os métodos das pesquisas e as taxas de respostas diferem muito entre si. O recente estudo multicêntrico $G A^{2} L E N$ (Global Allergy and Asthma Network of Excellence) ${ }^{(11)}$, ao aplicar os critérios epidemiológicos descritos no EPOS 2007 (European Positian Paper on Rhinosinusitis and Nasal Polyps ${ }^{(12)}$, permitiu estimar uma prevalência da RSC de 10,9\% na população europeia por meio de questionários enviados por correio. Nos Estados Unidos, o estudo realizado pelo Centro Nacional de Estatísticas em Saúde (National Center for Health Statistics - NCHS), mediante inquéritos populacionais domiciliares, estimou a prevalência de diagnóstico médico autorreferido de rinossinusite em $13 \%$ da população ${ }^{(13)}$. Chen et al. ${ }^{(14)}$ (2003) estimaram uma prevalência de 5\% no Canadá. Shashy et al. ${ }^{(15)}$ (2004) estimaram que aproximadamente $2 \%$ da população na cidade de Olmsted (Minnesota, EUA) apresentaria o diagnóstico de RSC segundo a análise dos registros médicos baseados no Código Internacional de Doenças (CID-9).

Dados epidemiológicos sobre a rinossinusite são raros e conflitantes na literatura médica. Isto contrasta com a grande quantidade de publicações 
sobre microbiologia, diagnóstico, tratamentos e repercussões econômicas desta doença ${ }^{(12,16)}$.

Não existem dados na literatura internacional sobre a prevalência de rinossinusite crônica obtidos em pesquisa domiciliar (face-to-face) de acordo com os critérios definidos pelo $E P^{3} \mathrm{OS}$, assim como não existem dados epidemiológicos sobre a prevalência dessa doença no Brasil. 
2 OBJETIVOS 


\section{OBJETIVOS}

\subsection{Objetivo principal}

Determinar a prevalência da rinossinusite crônica na cidade de São Paulo por meio de entrevistas domiciliares utilizando como diagnóstico o critério epidemiológico definido pelo $E P^{3} O S^{(12,16)}$.

\subsection{Objetivos secundários}

Analisar a associação de rinossinusite crônica com asma, rinite, tabagismo, renda familiar e escolaridade.

Criar um banco de dados regional, para efeito de comparação estatística com estudos subsequentes, a fim de medir as mudanças e avaliar a eficácia de intervenções realizadas. 
3 REVISÃO DE LITERATURA 


\section{REVISÃO DE LITERATURA}

\subsection{Diagnóstico de rinossinusite crônica}

A rinossinusite é a inflamação da mucosa dos seios paranasais e da cavidade nasal. Diversos critérios clínicos e procedimentos foram propostos nas últimas décadas para estabelecer o diagnóstico de rinossinusite como combinações de sintomas, temporalidade dos sintomas, coleta de material para cultura, exame físico por rinoscopia anterior ou endoscopia nasal, e utilização de exames radiológicos complementares.

Em 1996, a Academia Americana de Otorrinolaringologia promoveu um encontro entre especialistas, denominada "Força-Tarefa sobre Rinossinusite" (Task Force on Rhinosinusitis), para definir o diagnóstico da RS e suas classificações, com o intuito de uniformizar o critério diagnóstico a ser utilizado em pesquisas ${ }^{(17)}$. Conforme a associação entre a presença de determinados sintomas e o tempo de duração dos mesmos, a rinossinusite em adultos foi classificada em cinco categorias: aguda, subaguda, crônica, aguda recorrente e exacerbação aguda da RSC. Nesta classificação a RSC foi definida pela presença de dois ou mais sintomas maiores ou pela combinação de um sintoma maior e dois menores, com duração acima de 12 semanas $(\text { Tabela } 1)^{(17,18)}$. 
Tabela 1 - Sintomas maiores e menores para o diagnóstico clínico de rinossinusite

\begin{tabular}{l|l}
\hline \hline Sintomas Maiores & Sintomas Menores \\
\hline Dor / Pressão facial & Cefaléia \\
Obstrução nasal / Congestão & Halitose \\
Secreção nasal / retronasal purulenta & Dor em arcada dentária \\
Hiposmia / Anosmia & Tosse \\
Secreção nasal em exame físico & Otalgia ou pressão nos ouvidos \\
Febre (apenas para rinossinusite aguda) & Fadiga \\
\hline \hline
\end{tabular}

Fonte: Lanza, Kennedy (1997) ${ }^{(18)}$

Em 2002, uma nova Força-Tarefa nos Estados Unidos, promovida pela Sinus and Allergy Health Partnership (SAHP), envolveu diversos especialistas internacionalmente reconhecidos, que tratam e pesquisam a RSC para aperfeiçoar a sua definição. Houve uma preocupação em estabelecer critérios que poderiam ser utilizados por médicos de qualquer especialidade. Foi mantida a combinação entre sintomas maiores e menores por uma duração maior que 12 semanas e introduzida a exigência de se evidenciar sinais inflamatórios por meio do exame físico ou de imagem. Os sinais evidentes de inflamação crônica no exame físico que poderiam ser visualizadas por meio da rinoscopia anterior seriam: a presença de secreção purulenta, pólipos, edema ou eritema de mucosa do meato médio durante este período. ${ }^{(19)}$

Em 2007, a Academia Americana de Otorrinolaringologia publicou novas diretrizes sobre rinossinusites, elaboradas com base em evidências 
científicas, sendo modificados os critérios diagnósticos. A RSC foi definida de acordo com a presença, por um período maior do que 12 semanas, de dois ou mais dos sintomas seguintes: rinorreia purulenta (anterior, posterior ou ambas); obstrução nasal (ou congestão); dor ou pressão facial; e, redução do olfato. Além disso, seria obrigatória a evidência de inflamação das cavidades paranasais pela presença de uma ou mais das alterações, a saber: secreção purulenta ou edema no meato médio ou região etmoidal; pólipos na cavidade nasal ou meato médio (apenas por meio de exame endoscópico nasal); e/ou, exame de imagem que mostrasse a inflamação paranasal, sendo a tomografia computadorizada o exame padrão-ouro ${ }^{(20)}$.

Em 2007, foi publicado o European Position Paper on Rhinosinusitis and Nasal Polyps (EP $\left.{ }^{3} \mathrm{OS}\right){ }^{(12)}$, a partir do encontro de especialistas e pesquisadores renomados internacionalmente que revisaram a literatura científica e produziram uma extensa publicação sobre RS baseada em evidências, com objetivo de atualizar os conhecimentos sobre diagnóstico, exames subsidiários e tratamentos, e direcionar novas pesquisas. Nesta publicação, a RSC foi definida de acordo com a presença, por mais de 12 semanas, de dois ou mais sintomas, e um deles deveria, obrigatoriamente, ser um dos dois primeiros, a saber: a) obstrução (congestão) nasal; b) rinorreia (anterior ou posterior); c) dor/pressão facial; d) redução ou perda do olfato; e foi incluída a necessidade de evidenciar alterações inflamatórias no exame endoscópico nasal e/ou tomografia computadorizada. Uma publicação atualizada do $\mathrm{EP}^{3} \mathrm{OS}$, de 2012, reitera os mesmos critérios diagnósticos para rinossinusite em adultos ${ }^{(16)}$. Em suas duas edições é 
descrita a definição do diagnóstico de rinossinusite crônica para fins epidemiológicos (Quadro 1) baseada apenas na sintomatologia, sem necessidade de exame físico otorrinolaringológico ou de imagem.

Quadro 1 - Definição epidemiológica da Rinossinusite Crônica ${ }^{(12)}$

Presença de dois ou mais sintomas, e um deles deve ser: obstrução (congestão) nasal ou rinorreia (anterior ou posterior), acompanhados ou não de dor/pressão facial e/ou redução ou perda do olfato, com duração maior que 12 semanas, podendo ser confirmada por telefone ou entrevista.

\subsection{Epidemiologia}

Segundo Almeida Filho e Rouquayrol ${ }^{(21)}$ :

"Epidemiologia é a ciência que estuda o processo saúdeenfermidade na sociedade, analisando a distribuição populacional, e fatores determinantes do risco de doenças, agravos e eventos associados; propondo medidas específicas de prevenção, controle ou erradicação de enfermidades, promoção ou recuperação da saúde individual ou coletiva; produzindo informação e conhecimento para apoiar a tomada de decisão no planejamento, administração e avaliação de programas e ações de saúde. A determinação da prevalência indicará a quantidade de doentes na população em um determinado momento, e é um indicador valioso para o planejamento do setor de saúde." 
Em 2000, Van Cauwenberge e Watelet ${ }^{(22)}$ descreveram os problemas que seriam inerentes aos estudos epidemiológicos em RSC: a dificuldade na definição por causa da discrepância dos critérios diagnósticos como duração ou intensidade dos sintomas; a falta de comprovação por imagem e por cultura; a dificuldade na diferenciação de rinite e rinossinusite somente com dados clínicos; e, o fato de considerar a RSC como uma doença homogênea por falta de conhecimento de história natural e da fisiopatologia da RSC. Os autores ressaltaram a importância deste tipo de estudo, em razão de alto impacto econômico na saúde pública e na qualidade de vida do paciente, apesar das limitações do trabalho epidemiológico.

As publicações sobre a epidemiologia da RSC utilizaram diferentes metodologias de pesquisa para estimar a sua prevalência na população. Algumas pesquisas foram executadas por meio de entrevistas domiciliares ou telefônicas, em que a doença foi autorreferida pelo entrevistado; outras, em instituições de saúde mediante levantamento de dados registrados pelo médico, com auxílio do Código Internacional de Doenças (CID), o que torna difícil realizar comparações.

O inquérito de saúde de base populacional é uma ferramenta importante para a obtenção de informações necessárias e avaliação das políticas sociais e intervenções do setor de saúde. Plano de amostragem, qualidade e validade da informação e taxas de resposta são aspectos relevantes para obter dados confiáveis ${ }^{(23)}$. 
Nos Estados Unidos, o Inquérito Nacional de Entrevistas em Saúde (National Health Interview Survey - NHIS) é conduzido pelo Center for Disease Control and Prevention (CDC) e pelo NCHS para estimar a prevalência das doenças crônicas na população civil, não institucionalizada, e promover medidas de saúde pública. O objetivo principal deste inquérito é o monitoramento da saúde da população americana. Todos os anos, uma amostra representativa de domicílios, em todo o país, é selecionada por meio do desenho de amostragem complexa por conglomerados e em estágios múltiplos. Diversos questionários são aplicados nos residentes do domicílio sorteado, e um deles designado para avaliação de doenças crônicas em adultos no qual é selecionado aleatoriamente um adulto do domicílio sorteado, com idade igual ou superior a 18 anos, para responder sobre as condições crônicas. O relatório mais recente, publicado em 2012, definiu uma população elegível adulta de 35.153 pessoas, e foram coletados dados de 27.157 adultos. A taxa de resposta final para o questionário em adultos foi de $60,8 \%{ }^{(13)}$. A rinossinusite crônica foi definida por este questionário em virtude de resposta afirmativa à questão: "Nos últimos 12 meses, você teve sinusite diagnosticada por um médico ou profissional de saúde?". Os resultados apresentaram prevalências altas (Tabela 2) de rinossinusite (RS) que são citadas na maioria dos artigos médicos publicados referindo-se como prevalência de RSC. 
Tabela 2 - Prevalência de RS em adultos nos Estados Unidos, entre 1990 e 2010

\begin{tabular}{|c|c|}
\hline Ano & (\%) \\
\hline $1990-1992^{(22)}$ & $\begin{array}{c}\text { 135,6 a cada } 1.000 \text { pessoas } \\
34 \text { milhões de pessoas }\end{array}$ \\
\hline $2005^{(23)}$ & 13 \\
\hline $2006^{(24)}$ & 14 \\
\hline $2007^{(25)}$ & 11 \\
\hline $2008^{(26)}$ & 13 \\
\hline $2009^{(27)}$ & 13 \\
\hline $2010^{(13)}$ & 13 \\
\hline
\end{tabular}

Fonte: National Health Interview Survey ${ }^{(13,24-29)}$

Chen et al. ${ }^{(14)}$ (2003) realizaram um trabalho epidemiológico na população canadense analisando os dados do inquérito de saúde da população nacional, de 1996 a 1997. Este estudo aplicou um desenho de amostragem complexo, incorporando estratificação e múltiplos estágios de seleção para obtenção de amostra representativa da população e alcançaram taxa de resposta de $92,8 \%$. Foram entrevistadas, por telefone, 73.364 pessoas com 12 anos ou mais nos domicílios sorteados. No início da entrevista explicava-se que a pesquisa tinha objetivo de detectar doenças crônicas com sintomas persistentes por mais de seis meses e foram considerados como portadores de rinossinusite crônica os entrevistados que responderam afirmativamente a pergunta seguinte: "Você tem sinusite 
diagnosticada por um profissional de saúde?". A prevalência de rinossinusite autorreferida foi maior em mulheres $(5,7 \%)$ que em homens $(3,4 \%)$.

Shashy et al. ${ }^{(15)}$ (2004), por considerarem a questão utilizada no NHIS (“Você tem sinusite diagnosticada por um médico?"), passível de estimativas errôneas da prevalência da doença, discutiram em seu artigo as possíveis falhas desta metodologia como: a) a informação do diagnóstico ser fornecida pelo indivíduo; b) o indivíduo pode se autodenominar portador do diagnóstico de RSC por causa de sintomas que o sugerem ser portador da doença, porém nunca receberam este diagnóstico; c) o indivíduo pode ter recebido este diagnóstico erroneamente; e, d) o indivíduo pode ter tido rinossinusite tratada ou resolvida no passado mas continua a referir este diagnóstico. Estes autores consideraram a hipótese de que a prevalência publicada pelo NHIS poderia estar superestimada e realizaram uma pesquisa epidemiológica no condado de Omlsted (Minnesota, EUA), com auxílio de diagnósticos médicos de rinossinusite crônica registrados pelo CID-9 na Clínica Mayo, no ano 2000. Esta clínica é responsável pelo atendimento da maior parte da população desta região. A quantidade estimada de indivíduos com o diagnóstico de RSC foi de 1.995 a cada 100.000 pessoas, ou seja, aproximadamente $2 \%$ da população. Os autores reconheceram como limitação do estudo, o fato de que os pacientes com este diagnóstico poderiam não ter procurado auxílio médico ou mesmo poderia ter havido diagnóstico incorreto por parte do médico. 
Bhattacharyya $^{(5)}$ (2011) em seu artigo, também questionou os resultados da pesquisa americana realizada pela NHIS. Para ele, a maneira como foi definida a presença de "sinusite" não se refere necessariamente a casos crônicos, apesar da prevalência estimada por este estudo ser amplamente extrapolada como RSC na literatura otorrinolaringológica internacional. O autor analisou o Painel de Levantamento de Despesas Médicas (Medical Expenditure Panel Survey), de 2007, capaz de medir gastos atribuídos a determinadas doenças, em particular as registradas pelo Código Internacional de Doenças. Desta forma, analisando registros médicos de RSC, com esta doença foi estimado um gasto de US\$8,6 bilhões de dólares, em 2007, e uma prevalência de RSC em 4,9\% $\pm 0,2 \%$ da população que procurou auxílio médico e recebeu este diagnóstico. Contudo, o autor ressaltou que a metodologia desta pesquisa não foi especificamente designada para estimar prevalências e que este dado deveria ser analisado com cautela.

Kim et al. ${ }^{(30)}$ (2011) realizaram uma pesquisa por inquérito de base populacional mediante amostragem complexa por conglomerados e estágios múltiplos, envolvendo 4.098 indivíduos em 18 províncias e 180 distritos da Coréia do Sul, de janeiro a dezembro de 2008. Uma equipe médica com um otorrinolaringologista visitou domicílios e registrou entrevistas de participantes com 12 anos ou mais. O diagnóstico de rinossinusite crônica foi definido pela resposta positiva aos sintomas de obstrução nasal e rinorreia por mais de três meses e, ao mesmo tempo, pelo exame endoscópico com achados de secreção na cavidade nasal ou pólipos. A prevalência estimada 
de RSC na Coréia do Sul foi de 6,95\% sendo maior em homens do que em mulheres $(8,24 \%$ vs. $6,00 \% ; p=0,005)$

Em 2011, Hastan et al. ${ }^{(11)}$ publicaram parte dos resultados do estudo multicêntrico GA ${ }^{2}$ LEN (Global Allergy and Asthma Network of Excellence), relativo à investigação da epidemiologia da RSC na população europeia. Um questionário foi enviado pelo correio para uma amostra randomizada de adultos entre 15 e 75 anos, em 19 centros da Europa, abrangendo 12 países. O critério diagnóstico utilizado foi a definição epidemiológica publicada no $\mathrm{EP}^{3} \mathrm{OS}{ }^{(12,16)}$. Foram respondidos 57.128 questionários e a taxa de resposta total foi de $48 \%$, porém, com grande variação entre os centros (23,2\% a $80,3 \%$ ). A prevalência estimada de RSC na Europa foi de 10,9\% $(6,9 \%-27,1)$.

\subsection{Validação do critério epidemiológico de RSC}

O critério epidemiológico definido pelo $E P^{3} O S^{(12)}$ para diagnosticar indivíduos com RSC foi escolhido pelo estudo europeu GA ${ }^{2}$ LEN ${ }^{(11)}$. Este estudo também questionou se o indivíduo havia sido diagnosticado com RSC por um médico (diagnóstico autorreferido) e mostrou uma correlação alta (Pearson rho $=0,76 ; p<0,01)$ entre o diagnóstico médico autorreferido e o diagnóstico de acordo com os sintomas do $E P^{3} O S$. A prevalência do 
diagnóstico médico autorreferido foi menor que a prevalência pelos critérios do $E P^{3} \mathrm{OS}$ em todos os centros. ${ }^{(11)}$

Em 2010, Tomassen et al. ${ }^{(31)}$ publicaram artigo sobre a consistência e validade do critério epidemiológico de RSC, definido pelo $E P^{3} O S$ sendo utilizados dados do inquérito europeu GA²LEN. O estudo foi dividido em duas fases. Na primeira fase, os questionários foram enviados pelo correio para, ao menos, 3.000 indivíduos com idades entre 15 e 75 anos em cada um dos 11 centros participantes e foram respondidos 36.790 questionários. $\mathrm{Na}$ segunda fase, foi convocado um total de 1.700 indivíduos que participaram da primeira fase. Cada um dos 11 centros convocou 120 indivíduos com asma, 120 com RSC, 40 com asma e RSC e 120 sem asma e sem RSC. A correlação entre os dois questionários demonstrou uma concordância satisfatória a moderada ( $k a p p a=0,396)$ nas duas ocasiões. Durante a segunda fase do estudo, 342 indivíduos em dois centros realizaram endoscopia nasal e o examinador não tinha acesso aos sintomas do paciente. O diagnóstico epidemiológico conforme o $E P^{3} \mathrm{OS}$ mostrou-se significativamente associado à endoscopia positiva (OR 2,62; IC 95\% 1,57$4,39 ; p<0,001)$. Este estudo também mostrou associação entre o diagnóstico epidemiológico por sintomas do $E^{3} \mathrm{OS}$ o e o diagnóstico médico autorreferido de rinossinusite crônica em todos os indivíduos (OR 3,67; IC $95 \%$ 2,03-6,60; $\mathrm{p}<0,001)$. Os autores concluíram que, conforme o critério epidemiológico do EP3 OS, o diagnóstico por sintomas mostrou uma confiabilidade moderada em duas ocasiões, permaneceu estável entre diferentes centros, não foi influenciado pela presença de rinite alérgica e 
seria aplicável para avaliação em diferentes localizações geográficas para estimar a prevalência de RSC.

\subsection{RSC e Asma}

Asma é uma doença inflamatória crônica das vias aéreas associada a hiperresponsividade das vias aéreas levando a episódios de sibilos, dispneia, opressão torácica e tosse, consequentes da obstrução ao fluxo aéreo intrapulmonar, reversível espontaneamente ou com tratamento ${ }^{(32)}$. A RSC é a comorbidade mais comum em pacientes com asma, e esta associação leva à maior gravidade da doença pulmonar.

Jarvis et al. ${ }^{(33)}$ (2012), no estudo epidemiológico GA²LEN, mostraram uma forte associação entre asma e RSC (OR 3,47; IC 95\% 3,20-3,76) em todas as faixas etárias. Esta associação foi ainda maior em indivíduos também portadores de rinite alérgica (OR 11,85; IC 95\% 10,57-13,17). A RSC, na ausência de sintomas alérgicos nasais, foi positivamente associada à asma de início tardio.

Bhattacharyya e Kepnes $^{(34)}$ (2009) analisaram dados da NIHS de 11.813 indivíduos com asma associada ou não à rinite e/ou rinossinusite, entre 1997 e 2006. A presença destas doenças respiratórias foi verificada por meio de diagnósticos médicos autorreferidos. Pacientes com 0 diagnóstico de asma e rinossinusite apresentaram mais visitas à sala de 
emergência que pacientes apenas com asma $(p<0,001)$ ou com asma e rinite $(p<0,001)$. A prevalência de pacientes asmáticos com rinossinusite foi $40 \%$ maior que a prevalência de asma e rinite $29 \%$. Estes dados sugeriram uma associação importante entre a rinossinusite e a asma.

Outros estudos clínicos mostraram que RSC está associada à asma severa ${ }^{(35-38)}$. Liou et al. ${ }^{(37)}(2003)$ avaliaram causas e fatores que contribuem para a gravidade da asma em 149 pacientes asmáticos e houve associação entre a presença de RSC com asma de maior gravidade (OR 2,22; IC 95\% 1,08-4,60; $p=0,03)$. Um estudo realizado na Suécia permitiu constatar que os sintomas de obstrução nasal e rinorreia, por mais de 12 semanas, foram mais comuns em asmáticos com múltiplos sintomas respiratórios (asma mais grave) do que naqueles com poucos sintomas respiratórios ${ }^{(38)}$.

Distintos estudos publicaram a associação de RSC com pólipos à asma ${ }^{(39,40)}$ e mostraram que $30 \%$ dos pacientes com RSC com pólipos tem asma associada, enquanto $7 \%$ dos asmáticos apresenta RSC com pólipos $(12,41)$.

Bachert et al. ${ }^{(39)}$ (2010) publicaram um estudo de coorte com amostras de 600 pacientes em nove centros europeus em que analisaram a distribuição da doença na via aérea inferior, em diferentes grupos de pacientes com RSC. A asma brônquica estava presente em $45 \%$ dos pacientes com RSC com polipose nasossinusal. 


\subsection{RSC e Rinite}

Rinite é uma doença com alta prevalência na população adulta. É definida como inflamação da mucosa nasal e é caracterizada por sintomas nasais que incluem coriza, prurido, espirros e/ou obstrução nasal. Rinite alérgica é a forma mais comum das rinites não infecciosas e é associada a uma resposta IgE mediada contra alérgenos. Além disso, muitas outras condições não alérgicas podem desencadear os sintomas irritativos nasais, e é denominada rinite não alérgica. A RSC e a rinite podem coexistir no mesmo indivíduo, porém não está estabelecida uma relação causal entre estas doenças ${ }^{(42,43)}$.

Bachert et al. ${ }^{(44)}$ (2006) publicaram uma pesquisa realizada com 4959 indivíduos na Bélgica por meio de questionários enviados pelo correio, para identificar a prevalência da rinite alérgica (RA) e não alérgica (RNA). $O$ questionário incluía perguntas sobre os sintomas de rinite e seus fatores desencadeantes. A prevalência estimada foi de $29,8 \%$ da população com RA e $9,6 \%$ com RNA. A atopia pode aumentar o risco para o desenvolvimento de asma em pacientes com rinite alérgica ${ }^{(39)}$. Entretanto, a rinite é também um fator de risco para asma em pacientes não atópicos ${ }^{(39)}$.

Houser e Keen ${ }^{(45)}(2008)$ mostraram uma proporção alta de pacientes $(56,4 \%)$ com rinite alérgica comprovada (prick test e RAST) entre pacientes submetidos a sinusectomia, sugerindo uma relação causal. Contudo, o 
modelo de estudo retrospectivo escolhido não era adequado para esta inferência.

Tan et al. ${ }^{(46)}$ (2011) obtiveram 82,4\% de testes cutâneos alérgicos por puntura positivos para um ou mais antígenos em pacientes com RSC refratária ao tratamento clínico.

Berrettini et al. ${ }^{(47)}(1999)$ encontraram a lgE mediada para alérgenos ambientais em $67,5 \%$ dos pacientes com RSC e em $33,4 \%$ do grupo controle, e os pacientes com RSC tipicamente sensibilizados para alérgenos perenes ao invés de sazonais.

Sedaghat et al. ${ }^{(48)}$ (2012) compararam de forma retrospectiva os pacientes com rinite alérgica acompanhados em hospital terciário com pacientes que inicialmente receberam diagnóstico de RA, porém, posteriormente, desenvolveram RSC. Nestes pacientes alérgicos, não houve associação do surgimento de RSC com idade, tabagismo, rinossinusite aguda recorrente, asma, intolerância ao ácido acetil salicílico ou classificação da rinite em intermitente ou persistente.

Nos inquéritos epidemiológicos de base populacional, Chen et al. ${ }^{(14)}$ (2003) no Canadá, também mostraram uma associação estatisticamente significativa entre RSC e alergia, tanto em homens (OR 3,46; IC 95\% 2,574,65) quanto em mulheres (OR 3,30; IC 95\% 2,77-3,94). Na Coréia do Sul, Kim et al. ${ }^{(30)}$ (2011) encontraram maior prevalência de RSC em pacientes com rinite alérgica ( $16,5 \%$ vs. $3.62 \%$ ) e uma associação estatisticamente significativa entre RSC e rinite alérgica persistente moderada/severa (OR 
8,23; IC 95\% 4,70-14,43; $p=0,000)$. Esta associação foi a maior entre todos os fatores de risco analisados. Na Europa, no estudo GA ${ }^{2}$ LEN, $56,7 \%$ dos indivíduos com critério epidemiológico para RSC reportaram sintomas alérgicos nasais ${ }^{(11)}$.

A RA e a RSC são caracterizadas pela inflamação, porém o papel da alergia como mecanismo imunopatológico causando inflamação e RSC continua controverso ${ }^{(49)}$, entretanto, recomenda-se que os pacientes com RSC sejam avaliados quanto ao diagnóstico de rinite alérgica, inclusive por meio da realização de testes alérgicos. Desta forma, a terapia apropriada pode ser instituída ${ }^{(50)}$.

\subsection{RSC e Tabagismo}

A mucosa do epitélio respiratório é exposta a inúmeros poluentes inalatórios que podem contribuir para os sintomas e doenças do sistema respiratório. A fumaça do cigarro é um irritante reconhecido que pode provocar inflamação da via aérea e ter efeitos adversos no clearance mucociliar. Lieu e Feinstein ${ }^{(51)}$ (2000), observaram que os tabagistas apresentavam uma prevalência maior de RSC ou RSA recorrente, quando comparados às pessoas não tabagistas ou ex-tabagistas, porém não referiam aumento da prevalência entre os expostos passivamente ao tabaco. 
Nos estudos epidemiológicos por inquérito de base populacional, no Canadá, Chen et al. ${ }^{(14)}$ (2003) mostraram uma associação significativa entre rinossinusite crônica e tabagismo apenas no gênero feminino $(O R=1,57$; IC 95\% 1,24-1,99) independente da presença ou não de alergia. Não houve associação de RSC e tabagismo no gênero masculino (OR =1,24; IC 95\% $0,90-1,70)$.

$\mathrm{Na}$ amostra estudada por Kim et al. ${ }^{(30)}$ (2011) na Coréia do Sul, o tabagismo ativo não apresentou associação estatisticamente significativa.

$\mathrm{Na}$ Europa, a prevalência de tabagistas variou de $9,8 \%$ a $30,8 \%$ nos centros estudados. Houve uma associação significativa entre RSC e ser extabagista (OR 1,28; IC 95\% 1,18-1,38) e uma associação forte entre RSC e tabagismo ativo (OR 1,91; IC 95\% 1,77-2,05) ${ }^{(11)}$.

As possíveis explicações fisiopatológicas para RSC incluem alteração na imunidade inata da mucosa, alteração na regulação inflamatória, biofilmes bacterianos e fungos. A formação de biofilmes é um mecanismo importante na sobrevivência dos microrganismos para adesão às superfícies. Na última década, alguns estudos têm mostrado o papel do biofilme bacteriano na rinossinusite crônica ${ }^{(52,53)}$. Algumas das explicações para a presença de RSC em tabagistas pode ser o efeito da fumaça de cigarro sobre a função ciliar da mucosa nasal ${ }^{(54)}$ e a maior predisposição para a formação de biofilmes nas fossas nasais de tabagistas ${ }^{(55)}$.

Em estudo recente, Goldstein-Daruech et al. ${ }^{(55)}$ (2011) realizaram coleta de secreção nasal de pacientes com RSC, tabagistas e não 
tabagistas, e expuseram todas as culturas à fumaça do tabaco (in vitro) por 3 horas e posteriormente analisaram a formação de biofilmes. A exposição aguda (in vitro) ao tabaco aumentou a formação de biofilmes em 12 das 16 culturas de tabagistas e não houve aumento da formação de biofilmes em nenhuma das 18 culturas de não tabagistas. Posteriormente, as culturas provenientes de não tabagistas foram expostas à fumaça de tabaco por 3 horas ao dia durante quatro dias seguidos e todas as culturas iniciaram formação de biofilme. Os resultados sugeriram que as bactérias isoladas de tabagistas são mais suscetíveis à formação de biofilmes, em resposta à exposição ao tabaco do que as bactérias de não tabagistas. Além disso, bactérias de não tabagistas desenvolveram a habilidade de produzir biofilmes quando expostas ao tabaco in vitro. A exposição ao tabaco pode ter induzido alterações no ciclo de vida bacteriano resultando em formação de biofilmes.

\subsection{RSC e Fatores socioeconômicos}

Com relação ao nível socioeconômico, Kilty et al. ${ }^{(56)}$ (2011) avaliaram 127 pacientes com RSC por meio de questionário de doença-específica (SNAQ11) e escore tomográfico de Lund-MacKay e encontraram renda familiar baixa associada à maior severidade de sintomas nasossinusais (OLS 6,89; $p=0,05$ ) apesar de não haver diferença no escore tomográfico. 
Chen et al. ${ }^{(14)}$ (2003) encontraram uma associação estatisticamente significativa entre RSC e renda baixa tanto em homens (OR 2,06; IC 95\% 1,30-3,27) quanto em mulheres (OR 1,37; IC 95\% 1,05-1,79). Não houve associação estatística significativa de RSC em relação à quantidade de habitantes do domicílio, quantidade de quartos e nível educacional.

Kim et al ${ }^{(30)}$ (2011), na Coréia do Sul, não encontraram associação entre renda baixa e presença de RSC (OR 0,86; IC 95\% 0,67-1,11) e entre nível de escolaridade e presença de RSC (OR 1,35; IC 95\% 0,96-1,91). 
4 MÉTODOS 


\section{MÉTODOS}

\subsection{Aspecto ético}

O presente estudo obteve aprovação da Comissão de Ética para Análise de Projetos de Pesquisa (CAPPesq) do Hospital das Clínicas da Faculdade de Medicina da Universidade de São Paulo (HCFMUSP), sob o protocolo de pesquisa $n^{\circ}$ 0399/09. (Apêndice 1)

\subsection{Auxílio pesquisa}

O projeto de pesquisa contou com auxílio financeiro da FAPESP (Fundação de Amparo à Pesquisa do Estado de São Paulo) sob o processo número 2009/00574-1 e da Associação Brasileira de Otorrinolaringologia e Cirurgia Cérvico Facial (ABORLCCF) para sua execução.

\subsection{Tipo de estudo}

Inquérito transversal de base populacional (survey). 


\subsection{Plano de amostragem - Cálculo do tamanho da amostra}

População de estudo

A população de estudo era constituída por residentes da área urbana ${ }^{1}$ do município de São Paulo.

Frente aos objetivos do estudo, foram considerados quatro grupos de idade, para os quais foram obtidas estimativas independentes da prevalência de rinossinusite crônica. Esses grupos (crianças menores de 12 anos, adolescentes entre 12 anos completos e 19 anos, adultos entre 20 anos completos e 59 anos, e idosos com 60 anos ou mais de idade) foram considerados domínios de estudo. Na Tabela 3 estão apresentados os dados referentes à população de acordo com o Censo Demográfico do ano 2000, distribuída segundo os grupos etários de interesse.

Tabela 3 - População residente no Município de São Paulo, segundo a idade de acordo com o Censo Demográfico do ano 2000

\begin{tabular}{lcc}
\hline \hline Idade (anos) & População & $\%$ \\
\hline$<12$ & 1.876 .831 & 19,12 \\
12 a 19 & 1.431 .705 & 14,59 \\
20 a 59 & 5.551 .894 & 56,58 \\
$\geq 60$ & 952.757 & 9,71 \\
\hline Total & 9.813 .187 & 100,00 \\
\hline \hline
\end{tabular}

\% = porcento; Fonte: IBGE - SIDRA $^{(5)}$

1 Residentes em setores censitários urbanos (área urbanizada, não urbanizada e urbanizada isolada) e que são constituídos por domicílios particulares ou coletivos não institucionais. 
Tamanho da amostra

Uma vez que os parâmetros populacionais são estimados em proporções, para fins de cálculo do tamanho da amostra, foi utilizada a expressão algébrica seguinte ${ }^{(58,59)}$ :

$$
n=\frac{P \cdot(1-P)}{(d / z)^{2}} \cdot d e f f
$$

Onde:

$P=$ proporção estimada de indivíduos;

$d=0,04$ é o erro de amostragem a ser tolerado;

$z=1,96$ é o valor da curva normal correspondente ao nível de confiança de 95\% dos intervalos de confiança a serem construídos;

deff $=1,5$ é o efeito do delineamento esperado em função do sorteio de conglomerados (setores censitários).

Ao aplicar os valores acima, o tamanho de amostra foi calculado em, no mínimo, 325 pessoas por grupo etário.

Para manter a proporcionalidade da amostra e garantir que em todos os grupos etários fossem entrevistadas no mínimo 325 pessoas, o tamanho final da amostra seria de 3.351 (segunda coluna da Tabela 2). No entanto, por ser excessiva a quantidade prevista de adultos entre 20 e 59 anos de idade, foi proposto que para eles o tamanho da amostra fosse diminuído para a metade, de modo que o tamanho final da amostra fosse de 2.403 pessoas (terceira coluna da Tabela 2).

Essa distribuição não proporcional da amostra pelos grupos etários faz com que as probabilidades de sorteio (frações de amostragem) em cada 
grupo sejam distintas e como consequência, levando à necessidade de introdução de pesos para obter estimativas referentes ao conjunto da população (quarta coluna da Tabela 4).

Tabela 4 - Tamanho de amostras proporcionais, planejadas e pesos, segundo a idade

\begin{tabular}{lccc}
\hline \hline Idade (anos) & $\begin{array}{c}\text { Amostra } \\
\text { proporcional }\end{array}$ & $\begin{array}{c}\text { Amostra } \\
\text { planejada }\end{array}$ & Pesos \\
\hline$<12$ & 641 & 641 & 1 \\
12 a 19 & 489 & 489 & 1 \\
20 a 59 & 1.896 & 948 & 2 \\
$\geq 60$ & 325 & 325 & 1 \\
\hline Total & 3.351 & 2.403 & \\
\hline \hline
\end{tabular}

Uma vez que os indivíduos foram entrevistados em seus domicílios, foi necessário determinar a quantidade mínima de domicílios sorteados para que fossem alcançados os tamanhos de amostras planejadas. Considerando-se que a quantidade de domicílios particulares permanentes urbanos contabilizados no município de São Paulo (Censo Demográfico de 2000) era de 2.827.849, estimou-se a média esperada de pessoas por domicílio (razão pessoas/domicílios) para cada faixa etária. A partir dessas médias foi calculada a quantidade de domicílios que foram visitados para atingir o tamanho de amostra previsto (Tabela 5). 
Tabela 5 - Razão pessoas / domicílios e quantidade de domicílios a serem visitados, segundo idade

\begin{tabular}{lcc}
\hline \hline Idade (anos) & $\begin{array}{c}\text { Razão } \\
\text { pessoas/domicílios }\end{array}$ & $\begin{array}{c}\text { Domicílios a serem } \\
\text { visitados }\end{array}$ \\
\hline$<12$ & 0,663696 & 966 \\
12 a 19 & 0,506288 & 966 \\
20 a 59 & 1,963292 & 483 \\
$\geq 60$ & 0,336919 & 966 \\
\hline \hline
\end{tabular}

Dessa forma, para alcançar as 2.403 entrevistas planejadas, a quantidade de domicílios visitados seria de 966 (arredondado para 1.000). Porém, para proteger dos efeitos da não resposta e considerando que o porcentual de pessoas selecionadas que não aceitariam responder ao questionário (casa fechada e recusa) poderia chegar a $20 \%$ e, ainda, considerando taxa de $10 \%$ de domicílios vagos, deveriam ser sorteados, no mínimo, 1.375 domicílios. Ao final, optou-se por uma quantidade de domicílios múltiplos de quatro, para que a divisão da amostra em quatro trimestres resultasse em amostras de tamanhos iguais. Dessa forma, o total de domicílios da amostra foi inicialmente determinado em 1.600.

Seguindo este planejamento, todas as pessoas menores de 20 anos ou maiores de 60 anos, residentes no domicílio, deveriam ser entrevistadas. E, em metade desses domicílios (um a cada dois), seriam entrevistadas as pessoas com 20 anos a 59 anos de idade. 
Critérios de inclusão

Foram incluídas na amostra deste estudo todas as pessoas residentes nos domicílios sorteados do município de São Paulo, seguindo o planejamento conforme o grupo etário.

Critérios de exclusão

Foram excluídas as pessoas que não residiam no domicílio visitado. Também foram excluídos os domicílios coletivos, casas comerciais e casas desabitadas e as pessoas dentro do domicílio que não aceitaram participar do estudo e que não assinaram o Termo de Consentimento Informado (Apêndice 2).

\subsection{Sorteio dos setores censitários}

O processo de amostragem foi realizado em dois estágios: setor censitário e domicílio.

Definido pelo IBGE, o setor censitário é uma unidade territorial de coleta das operações censitárias com limites físicos identificados, em áreas contínuas, e respeitando a divisão político-administrativa do Brasil. Apresenta dimensão e quantidade de domicílios que permitam o levantamento das informações por um único recenseador, em um território que abriga em média 300 domicílios. 


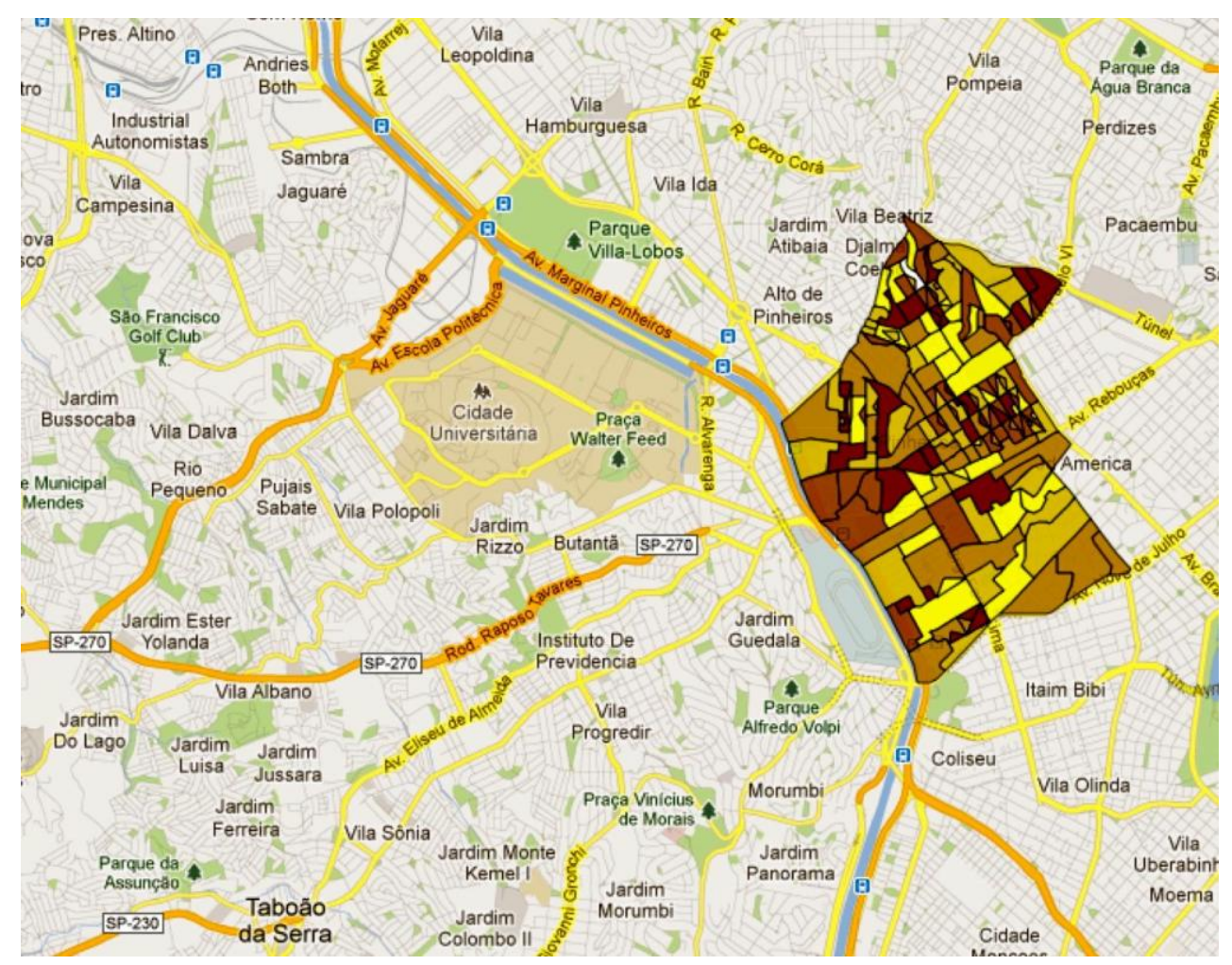

Figura 1 - No detalhe: distrito de Pinheiros e seus setores censitários.

Fonte: IBGE ${ }^{(60)}(2010)$

Para que a quantidade de entrevistas, por grupo etário, não excedesse 20 em cada setor censitário foram sorteados 50 setores censitários. Dessa forma, o efeito do desenho foi inferior a 1,5 (valor previsto no cálculo do tamanho da amostra) ${ }^{2}$.

Esse sorteio foi realizado a partir de uma listagem com todos os setores existentes no Município de São Paulo, montada para o Censo Demográfico do ano 2000. Dessa lista constam 13.278 setores, entre os quais $12.504(94,2 \%)$ pertencentes à área urbana do município (Tabela 6).

${ }^{2}$ deff $=1+\rho \cdot(\bar{b}-1)$ onde $\bar{b}=19$ é a quantidade de pessoas a serem entrevistadas por setor, no maior grupo etário e $p=0,025$ é o valor estimado para o grau de homogeneidade intraclasse. 
Foram excluídos os setores rurais, bem como os setores especiais, à exceção dos Especiais Aglomerados Urbanos, constituídos, em sua maioria, por favelas.

Tabela 6 - Setores censitários do Censo do IBGE (2000), classificados por situação e tipo

\begin{tabular}{lc|c}
\hline \hline Classificação dos setores & Censo (2000) & Amostra \\
\hline Situação & 12.416 & 49 \\
Área urbanizada & 2 & - \\
Área não urbanizada & 86 & 1 \\
Urbanizada isolada & 607 & \\
Rural de extensão urbana & 6 & \\
Rural povoado & - & \\
Rural núcleo & 23 & \\
Rural outros & 138 & \\
Rural exclusiva aglomerado & & \\
Tipo & 12.162 & 46 \\
Comum ou não especial & 1.067 & 4 \\
Esp. aglomerado subnormal & 2 & \\
Esp. quartéis, bases militares, etc. & 10 & \\
Esp. alojamento, acampamentos, etc. & - & \\
Esp. embarcações, barcos, navios, etc. & 2 & \\
Esp. aldeia indígena & 9 & \\
Esp. penitenciárias, cadeias, etc. & \multicolumn{2}{|c}{} \\
Esp. asilos, orfanatos, hospitais, etc. & 26 & \\
Total & 13.278 & 50 \\
\hline \hline
\end{tabular}


Antes do sorteio, os setores foram ordenados segundo o porcentual de responsáveis dos domicílios que possuíam 12 ou mais anos de estudo. Essa ordenação, associada à utilização de sorteio sistemático, produziu uma estratificação implícita da amostra, segundo a escolaridade do responsável pelo domicílio.

Os setores foram, ainda, sorteados com probabilidade proporcional ao tamanho, resultante da quantidade de domicílios.

\subsection{Sorteio dos domicílios}

No Anexo A estão listados os setores sorteados, com indicação do distrito a que pertencem. Para cada um deles, foi copiado o croqui da área, fornecido pelo IBGE.

De posse do croqui, pesquisadores de campo visitaram todos os setores da amostra para atualizar o mapa fornecido pelo IBGE, conferindo os limites do setor e os nomes das ruas (tanto as que constituem o limite do setor como as internas a ele) e identificando novas ruas, ruelas e passagens. Além dessa atividade, todos os endereços existentes no setor foram listados em formulário específico, identificando os endereços de domicílios e comerciais ("arrolamento de domicílios"). Todos os endereços referentes aos domicílios foram numerados excluindo-se aqueles em 
construção, sem possibilidade de ocupação durante o período de realização da pesquisa.

Inicialmente foram selecionados 32 domicílios, por meio de sorteio sistemático entre 1.600 domicílios da amostra, divididos em quatro trimestres ou estações, nomeadas conforme as estações do ano.

As frações de amostragem de cada grupo etário são:

Menores de 20 anos e maiores de 60 anos $\rightarrow$

$$
f=\frac{50 . M_{i}}{M} \cdot \frac{32}{M_{i}^{\prime}}=\frac{1.600}{2.827 .849}=\frac{1}{1.767,4056}
$$

Adultos de 20 anos a 59 anos $\rightarrow$

$$
f=\frac{50 . M_{i}}{M} \cdot \frac{32 / 2}{M^{\prime}{ }_{i}}=\frac{800}{2.827 .849}=\frac{1}{3.543,8112}
$$

Onde,

$M=$ quantidade de domićlios no Município de São Paulo no ano 2000 $(M=2827849)$;

$M_{i}=$ quantidade de domicílios no setor censitário i no Censo do ano 2000; e, $M_{i}^{\prime}=$ quantidade de domicílios arrolados no setor censitário $i$.

Os 'Pesos' foram resultado da razão $M$ ' $/ M_{i}$ e considerados na análise de dados.

\subsection{Processo de amostragem - Adequações na fase de campo}

Foram realizadas reuniões periódicas com a equipe de estatísticos populacionais para análise do processo de amostragem e realização de 
adequações da amostra, conforme as condições encontradas durante a pesquisa de campo.

Ao visitarem o setor de número 355030823000009, correspondente a uma favela no distrito de Cidade Dutra, os pesquisadores de campo foram informados de que a favela seria removida. Decidiu-se pela exclusão desse setor, considerando-se que, com os 49 setores restantes as estimativas previstas na pesquisa seriam obtidas sem comprometimento da precisão desejada. Em nova visita feita ao local após o início das entrevistas foi verificado que parte importante das residências já havia sido, de fato, removida.

As frações de amostragem correspondentes à primeira etapa de entrevistas (outono) foram:

Menores de 20 anos e maiores de 60 anos $\rightarrow$

$$
f=\frac{50 \cdot M_{i}}{M} \cdot \frac{8}{M_{i}}=\frac{400}{2.827 .849}=\frac{1}{7.069,6225}
$$

Adultos com idades entre 20 anos e 59 anos $\rightarrow$

$$
f=\frac{50 \cdot M_{i}}{M} \cdot \frac{4}{M_{i}}=\frac{200}{2.827 .849}=\frac{1}{14.139,2450}
$$

Após a avaliação das atividades de campo referentes à primeira estação (outono), observou-se a realização de uma quantidade de entrevistas maior que o previsto. Abaixo estão detalhadas duas razões para o ocorrido. 
Nas frações de amostragem constou o sorteio de 400 domicílios considerando os tamanhos dos setores no Censo demográfico do ano 2000, ou seja, foi mantida a fração de amostragem no sorteio, permitindo que a quantidade de domicílios sorteados fosse diferente do previsto, caso o setor tivesse mudado de tamanho.

Foi observada, ainda, uma taxa de resposta de $86 \%$, maior que os $80 \%$ previstos, o que também acarretou um acréscimo na quantidade de entrevistas.

Em função disso e para adequar-se ao orçamento do projeto, planejou-se uma diminuição da quantidade de domicílios sorteados para a segunda estação (inverno) - sete domicílios por setor, o mesmo ocorrendo na terceira e quarta estações (primavera e verão) - 6 seis domicílios por setor. As frações de amostragem passaram a ser no inverno:

Menores de 20 anos e maiores de 60 anos $\rightarrow$

$$
f=\frac{50 . M_{i}}{M} \cdot \frac{7}{M_{i}}=\frac{350}{2.827 .849}=\frac{1}{8.079,568571}
$$

Adultos com idades entre 20 anos e 59 anos $\rightarrow$

$$
f=\frac{50 . M_{i}}{M} \cdot \frac{3,5}{M_{i}}=\frac{175}{2.827 .849}=\frac{1}{1.615,13714}
$$

E, nas duas últimas estações, primavera e verão:

Menores de 20 anos e maiores de 60 anos $\rightarrow$

$$
f=\frac{50 \cdot M_{i}}{M} \cdot \frac{6}{M_{i}}=\frac{300}{2.827 .849}=\frac{1}{9.426,16333}
$$


Adultos com idades entre 20 anos e 59 anos $\rightarrow$

$$
f=\frac{50 \cdot M_{i}}{M} \cdot \frac{3}{M_{i}}=\frac{150}{2.827 .849}=\frac{1}{18.852,32667}
$$

Em função dessas diferenças nas frações de amostragem que representam as diferentes probabilidades de seleção utilizadas nos sorteio de domicílios, novos pesos foram associados às pessoas entrevistadas, conforme a estação do ano em que as entrevistas foram realizadas. $\mathrm{Na}$ Tabela 7, estão descritos os pesos utilizados.

Tabela 7 - Pesos segundo estação e faixa etária

\begin{tabular}{l|c|c|c|c}
\hline \hline \multirow{2}{*}{ Estação } & \multicolumn{2}{|c|}{ Peso } & \multicolumn{2}{c}{ Peso relativo } \\
\cline { 2 - 5 } & $\begin{array}{c}<\mathbf{2 0} \text { anos e } \\
>59 \text { anos }\end{array}$ & $\begin{array}{c}\text { entre } \\
\text { 20 e 59 anos }\end{array}$ & $\begin{array}{c}<\mathbf{2 0} \text { anos e } \\
>59 \text { anos }\end{array}$ & $\begin{array}{c}\text { entre } \\
\text { 20 e 59 anos }\end{array}$ \\
\hline Outono & $7.069,62250$ & $14.139,24500$ & 1 & 2 \\
Inverno & $8.079,56857$ & $16.159,13714$ & 1,14286 & 2,28571 \\
Primavera & $9.426,16333$ & $18.852,32667$ & 1,33333 & 2,66667 \\
Verão & $9.426,16333$ & $18.852,32667$ & 1,33333 & 2,66667 \\
\hline \hline
\end{tabular}

\subsection{Preparação e coleta de dados nos domicílios}

Foram contratados supervisores e entrevistadores especializados em coletas de inquéritos de base domiciliar, e a supervisão e todas as 
entrevistas remuneradas. Em fevereiro de 2010, foi realizado o treinamento dos supervisores e entrevistadores por meio de aula expositiva que abordou a definição e classificação de rinossinusite, e conceitos sobre sintomas e diagnóstico diferencial entre rinite, gripe, resfriado, rinossinusite aguda bacteriana e rinossinusite crônica. Posteriormente foi ministrada aula prática com aplicação do questionário e esclarecimento de dúvidas sobre seu preenchimento.

Duas semanas antes do início das entrevistas, foi feita uma ampla divulgação na mídia (rádio, jornal, internet e televisão) sobre a pesquisa com o intuito de melhorar a aceitação das entrevistas. Nos setores censitários de maior nível sócio econômico e, geralmente, com maior dificuldade no recebimento do entrevistador, foram enviadas cartas registradas com timbre da Universidade de São Paulo, informando ao morador que seu domicilio havia sido sorteado e que em breve ele receberia a visita do entrevistador da pesquisa. Também foi feito contato com administradoras e com os síndicos de edifícios para orientá-los sobre a idoneidade do projeto.

Foi divulgado um número de telefone exclusivo para a pesquisa para contato com a supervisão e com a pesquisadora com intuito de esclarecer dúvidas tanto dos entrevistadores quanto dos entrevistados.

Os entrevistadores foram treinados quanto à abordagem e postura, sendo recomendado uso de avental e crachá. Em seu material, além dos questionários, apresentavam as cartas explicativas sobre a pesquisa e 
entregavam cópias das matérias veiculadas na mídia para auxiliar a permissão à visita domiciliar do entrevistador.

Foi dada a recomendação de que os entrevistadores não citassem, durante a sua apresentação, que a pesquisa seria sobre "sinusite", e foi sugerido informar que se tratava de questões sobre "doenças respiratórias", para que o entrevistado não ficasse sugestionado.

A coleta de dados no presente estudo foi iniciada em 21 de março de 2010 e terminada em 20 de março de 2011, e foi dividida em quatro etapas coincidentes com as estações do ano: o outono a primeira estação da pesquisa, seguida do inverno, primavera e verão. A quantidade total de domicílios visitados foi dividida entre as quatro estações do ano para reduzir efeito de mais respostas positivas próximo ao inverno e para permitir adequações durante o processo de amostragem.

Os entrevistadores seguiam cronograma de três meses para efetuar as entrevistas nos domicílios sorteados em cada estação. Para aumentar a taxa de resposta, foi recomendado que se visitasse o domicílio todas as vezes que estivessem no setor enquanto não houvesse uma recusa formal à pesquisa, e além de material explicativo era oferecido agendamento da entrevista em uma data e horário oportuno.

Todos os indivíduos entrevistados assinaram consentimento informado. O termo de consentimento e o questionário deveriam ser assinados e respondidos apenas por outra pessoa responsável, se a idade do entrevistado fosse inferior a 12 anos. 
Em reuniões semanais os entrevistadores recebiam o material para as entrevistas e retornavam os questionários preenchidos, os quais passavam por conferência das supervisoras para verificação de possíveis inconsistências. Relatórios com a quantidade de entrevistas e recusas, domicílios visitados e fechados eram obtidos mensalmente e analisados pela pesquisadora e pela equipe de estatísticos populacionais.

Os dados coletados foram digitados duplamente por digitadores treinados. Para confirmação da visita dos entrevistadores e da concordância das respostas, foi feito contato telefônico em uma amostra aleatória de 3\% dos entrevistados para responder novamente algumas questões.

\subsection{Definição das variáveis do estudo}

Conforme sugerido no EP OS dos anos 2007 e 2012, a definição epidemiológica de rinossinusite crônica é definida pela presença de dois ou mais sintomas, sendo um deles obrigatoriamente: 1. Obstrução nasal / congestão nasal ou 2. Rinorréia (anterior ou posterior). Os outros sintomas avaliados são: 3. Dor ou pressão facial e 4. Redução ou perda do olfato. Os sintomas devem estar presentes por mais de 12 semanas ${ }^{(12,16)}$.

Durante a aplicação do questionário (Anexo B), o diagnóstico de rinossinusite crônica foi realizado em duas etapas. Primeiro, foi questionado sobre a duração dos sintomas obrigatórios, obstrução nasal e secreção 
nasal nos últimos 12 meses, classificando a resposta em: a) ausência do sintoma; b) menos de 10 dias; c) de 10 dias a 3 meses; d) maior que 3 meses, registrando o episódio de maior permanência do sintoma. Durante este questionamento o entrevistador mostrava um cartão com as alternativas de temporalidade para facilitar a determinação do período exato. O passo seguinte foi questionar a presença dos sintomas de dor ou pressão facial e redução de olfato. Consideramos a presença destes dois últimos sintomas apenas se estivessem presentes durante o período do sintoma obrigatório.

Asma foi definida mediante resposta positiva à questão: "Nos últimos 12 meses, algum médico disse que você tem asma ou chiado no peito?". Rinite foi definida pela resposta positiva à questão: "Nos últimos 12 meses, algum médico disse que você tem rinite?". Dados sobre tabagismo (fumante, ex-fumante ou nunca fumou), tempo e quantidade de cigarros consumidos, tabagismo passivo (definido pela resposta positiva à questão "Alguém fuma em seu domicílio?"), renda mensal e anos de escolaridade do chefe da família e características do domicílio também foram questionados.

O diagnóstico médico autorreferido de rinossinusite foi definido por resposta positiva à questão "Nos últimos 12 meses, você teve o diagnóstico de sinusite feito por um médico?" (questão semelhante à utilizada na pesquisa nacional americana pela NHIS) ${ }^{(13)}$. Aos que respondiam positivamente perguntava-se se tinham conhecimento se o diagnóstico era de doença aguda ou crônica. 
Em 2007, o projeto epidemiológico foi idealizado e iniciou-se a elaboração do questionário que seria aplicado na amostra do estudo, amplamente discutido com especialistas do grupo de Rinologia do HCFMUSP e em reuniões metodológicas, e, por diversas vezes, foram incorporadas sugestões para melhoria do instrumento, até a sua versão final.

Um estudo preliminar foi realizado para a adequação das questões e cálculo do tempo de entrevista com 80 pacientes de um hospital terciário atendidos no Departamento de Otorrinolaringologia e divididos em três grupos: rinossinusite aguda bacteriana, rinossinusite crônica e grupo controle (com diagnóstico de rinite ou queixas não nasossinusais). Uma concordância moderada foi obtida entre diagnóstico epidemiológico pelos critérios do questionário e o diagnóstico clínico pelo otorrinolaringologista conforme o $\mathrm{EP}^{3} \mathrm{OS}$, incluindo, além dos sintomas, as alterações na endoscopia nasal e/ou tomografia de seios da face (kappa=0,63).

\subsection{Análise estatística}

Conforme descrito previamente, na população de estudo foram considerados quatro grupos de idade, para os quais foram obtidas estimativas independentes da prevalência de rinossinusite crônica. Nesta tese, como não haveria nenhuma repercussão na análise de dados, optouse por exclusão da faixa etária pediátrica em decorrência de diversos 
fatores: a) para adequar a comparação entre estudos, pois os trabalhos publicados na literatura que descrevem a prevalência da RSC excluem idades abaixo de 12 anos; b) possibilidade de comorbidades frequentes como hipertrofia de adenoide como fator de confusão; e c) questionário respondido pelo responsável com questões tão peculiares como olfato e dor facial. Além disso, depois que havia sido decidido pela exclusão deste grupo etário, a publicação do $\operatorname{EP}^{3} \mathrm{OS}(2012)^{(16)}$ descreveu novos critérios diagnósticos para a população pediátrica substituindo a alteração do olfato pela presença de tosse.

As análises estatísticas foram processadas mediante uso do programa STATA versão 10.0, do qual se utilizou o módulo "SVY" adequado para obtenção de estimativas não viciadas quando os dados são provenientes de planos de amostragem complexos. Pesos de pósestratificação foram adicionados para ajuste da população segundo idade, gênero e escolaridade conforme o Censo demográfico do IBGE $(2010)^{(61)} \mathrm{e}$ a Pesquisa de Orçamentos Familiares $(2008-2009)^{(62)}$. Foi calculada a prevalência de rinossinusite crônica e o correspondente intervalo de confiança de $95 \%$ de acordo com as características individuais.

A significância da comparação entre variáveis qualitativas pesquisadas com o diagnóstico dos indivíduos (presença ou não de rinossinusite crônica) foi determinada pelo teste do chi-quadrado.

Foi adotado o valor alfa de significância $\leq 0,05$. 
5 RESULTADOS 


\section{RESULTADOS}

\subsection{Entrevistas realizadas e taxas de resposta}

A quantidade de entrevistas realizadas esteve muito próxima das planejadas. Para comparar esses valores, na Tabela 8 estão apresentados os tamanhos de amostra previstos e realizados para cada faixa etária, segundo o plano de amostragem.

Tabela 8 - Quantidade de entrevistas previstas na amostra e de entrevistas realizadas, São Paulo, SP, 2010-2011

\begin{tabular}{l|c|c}
\hline \hline Idade (anos) & Entrevistas previstas & Entrevistas realizadas \\
\hline 12 a 29 & 489 & 504 \\
20 a 59 & 948 & 1.032 \\
$\geq 60$ & 325 & 470 \\
Total & 1.762 & 2.006 \\
\hline \hline
\end{tabular}

Após as adequações durante o processo de amostragem foram sorteados 1.480 endereços, dos quais 110 foram descartados por não serem domicílios. Em 93,9\% dos 1.370 domicílios visitados, foi possível contatar algum morador para explicar a pesquisa e identificar as pessoas a serem entrevistadas. Ou seja, somente $6,1 \%$ dos domicílios sorteados mantiveram- 
se fechados em todas as visitas feitas ou possuíam moradores que se recusaram a receber o entrevistador ou a dar informações sobre os moradores existentes, o que corresponde a uma taxa de resposta de domicílios de 94\%.

Da população elegível, 93,5\% responderam o questionário, representando uma taxa de resposta total de $87,8 \%$.

\subsection{Dados da amostra}

Participaram da amostra 2.006 indivíduos com 12 ou mais anos de idade, porém três entrevistas foram excluídas da análise estatística por apresentarem questionários incompletos, totalizando 2.003 entrevistados. A idade média foi de 39,8 anos (DP 21, 12-92), 45,33\% (908/2.003×100) eram do gênero masculino; e 54,67\% (1.095/2.003×100) do feminino.

A prevalência da rinossinusite crônica na cidade de São Paulo foi de 5,51\% (IC 95\% 3,99-7,58). Não existiu diferença estatisticamente significativa na prevalência segundo o gênero [Masculino vs. Feminino: 5,04\% (IC 95\% 3,32-7,56) vs. 5,92\% (IC 95\% 4,17-8,34), p=0.41] (Tabela 9). A prevalência de rinossinusite autorreferida diagnosticada por um médico (sem distinção entre aguda e crônica) foi de 16,55\% (IC 95\% 14,18-19,23) (Tabela 10). 
Tabela 9 - Distribuição da amostra e prevalência da rinossinusite crônica em pessoas com 12 anos ou mais, segundo variáveis sociodemográficas, condições de saúde e estado tabágico, São Paulo, SP, 2010-2011

\begin{tabular}{|c|c|c|c|c|c|}
\hline Variáveis & $\mathbf{n}$ & $\begin{array}{c}\mathrm{n} \\
\mathrm{RSC}\end{array}$ & $\begin{array}{c}\text { RSC } \\
(\%)\end{array}$ & IC 95\% & p-valor \\
\hline \multicolumn{6}{|l|}{ Gênero } \\
\hline Masculino & 908 & 47 & 5,04 & {$[3,32-7,56]$} & 0,4125 \\
\hline Feminino & 1.095 & 57 & 5,92 & {$[4,17-8,34]$} & \\
\hline \multicolumn{6}{|c|}{ Quantidade de moradores no domicilio } \\
\hline$[1 ; 2]$ & 435 & 28 & 6,55 & {$[3,85-10,92]$} & 0,5046 \\
\hline 3 & 492 & 23 & 4,22 & {$[2,49,-7,08]$} & \\
\hline 4 & 516 & 24 & 5,05 & {$[3,29-7,68]$} & \\
\hline$[5 ; 20]$ & 560 & 29 & 6,47 & {$[3,63-11,28]$} & \\
\hline \multicolumn{6}{|c|}{ Quantidade de quartos no domicilio } \\
\hline 1 & 519 & 28 & 5,77 & {$[3,60-9,12]$} & 0,4282 \\
\hline 2 & 976 & 57 & 6,17 & {$[4,05-9,32]$} & \\
\hline 3 a 6 & 508 & 19 & 4,07 & {$[2,18-7,50]$} & \\
\hline \multicolumn{6}{|c|}{ Anos de estudo do chefe da família } \\
\hline$[0 ; 8]$ & 1030 & 51 & 4,74 & {$[3,28-6,79]$} & 0,6416 \\
\hline$[9 ; 11]$ & 626 & 35 & 6,13 & {$[3,79-9,76]$} & \\
\hline 12 ou mais & 347 & 18 & 6,05 & {$[3,16-11,26]$} & \\
\hline \multicolumn{6}{|c|}{ Renda mensal do chefe de família (salário mínimo) } \\
\hline$[0 ; 1]$ & 376 & 30 & 8,11 & {$[5.82-11.2]$} & 0,0677 \\
\hline$[2 ; 3]$ & 907 & 38 & 5,00 & {$[3.33-7.45]$} & \\
\hline 3 ou mais & 576 & 33 & 5,71 & [3.42 - 9.39] & \\
\hline Não sabe / não respondeu & 144 & 3 & 1,86 & {$[5.79-5.80]$} & \\
\hline \multicolumn{6}{|l|}{ Estado tabágico } \\
\hline Não tabagista & 1.378 & 64 & 4,95 & {$[3,39-7,17]$} & 0,4344 \\
\hline Tabagista & 289 & 18 & 6,53 & {$[3,36-12,30]$} & \\
\hline Ex-tabagista & 336 & 22 & 6,76 & {$[4,30-10,47]$} & \\
\hline Não tabagista & 1.378 & 64 & 4,95 & {$[3,39-7,17]$} & \\
\hline \multicolumn{6}{|c|}{ Consumo tabágico em anos $x$ maço } \\
\hline Menor ou igual a 10 & 152 & 7 & 5.21 & {$[2,33-11,24]$} & 0,3686 \\
\hline 11 ou mais & 133 & 11 & 8,45 & {$[4,08-16,66]$} & \\
\hline
\end{tabular}


Continuação da Tabela 9

\begin{tabular}{|c|c|c|c|c|c|}
\hline Variáveis & $\mathbf{n}$ & $\begin{array}{c}n \\
\mathbf{R S C}\end{array}$ & $\begin{array}{c}\text { RSC } \\
(\%)\end{array}$ & IC $95 \%$ & p-valor \\
\hline \multicolumn{6}{|c|}{ Tabagismo passivo (no domicílio) } \\
\hline Sim & 738 & 44 & 6,62 & {$[4.30-10.06]$} & 0,1819 \\
\hline Não & 1265 & 60 & 4,92 & {$[3.43-7.01]$} & \\
\hline \multicolumn{6}{|c|}{ Asma autorreferida diagnosticada por médico } \\
\hline Sim & 131 & 19 & 16,47 & {$[8,92-28,44]$} & 0,0001 \\
\hline Não & 1.868 & 84 & 4,82 & {$[3,47-6,67]$} & \\
\hline Não sabe / Não respondeu & 3 & 1 & - & - & \\
\hline \multicolumn{6}{|c|}{ Rinite autorreferida diagnosticada por médico } \\
\hline Sim & 351 & 53 & 15,14 & {$[10,81-20,80]$} & 0,0000 \\
\hline Não & 1.649 & 51 & 3,44 & {$[2,31-5,09]$} & \\
\hline Não sabe / Não respondeu & 3 & - & - & - & \\
\hline
\end{tabular}

$\overline{\mathrm{n}}$ = amostra; RSC = rinossinusite crônica; $\mathrm{IC}$ = intervalo de confiança

Tabela 10 - Prevalência de rinossinusite crônica (segundo critério epidemiológico $\left.E P^{3} \mathrm{OS}\right) \times$ prevalência de rinossinusite autorreferida, em pessoas com 12 anos ou mais, São Paulo, SP, 2010-2011

\begin{tabular}{c|c|c|c}
\hline $\begin{array}{c}\text { Prevalência de RSC pelos critérios de } \\
\text { sintomas do questionário }\end{array}$ & \multicolumn{2}{|c}{$\begin{array}{r}\text { Prevalência de rinossinusite } \\
\text { autorreferida diagnosticada por um } \\
\text { médico }\end{array}$} \\
\hline$\%$ & IC $95 \%$ & $\%$ & IC $95 \%$ \\
\hline 5,512 & {$[3,99-7,58]$} & 16,55 & {$[14,18-19,23]$} \\
\hline \hline
\end{tabular}

$\%=$ porcento; IC = intervalo de confiança

As prevalências de RSC segundo a quantidade de moradores no domicílio $(p=0,50)$, quantidade de quartos no domicílio $(p=0,43)$ e a quantidade de anos de estudo do chefe de família $(p=0,64)$ não mostrou uma diferença estatisticamente significativa (Tabela 9). Os subgrupos de 
renda mensal do chefe de família apresentaram uma diferença tendendo a significância estatística $(p=0,0677)$, com uma associação estatisticamente significativa entre o subgrupo de baixa renda (OR 2,24; IC 95\% 1,06-4,72; $\mathrm{p}=0,036)($ Tabela 11).

Tabela 11 - Razão de chances (odds ratio) de rinossinusite crônica, segundo características sociodemográficas e condições de saúde, São Paulo, SP, 2010-2011

\begin{tabular}{|c|c|c|c|}
\hline & \multicolumn{3}{|c|}{ RSC } \\
\hline & OR & IC 95\% & p-valor \\
\hline \multicolumn{4}{|l|}{ Gênero } \\
\hline Homens & 1 & & \\
\hline Mulheres & 1,19 & {$[0,78-1,80]$} & 0,413 \\
\hline \multicolumn{4}{|c|}{ Quantidade de moradores no domicilio } \\
\hline$[1 ; 2]$ & 1 & & \\
\hline 3 & 0,63 & {$[0,29-1,35]$} & 0,229 \\
\hline 4 & 0,76 & {$[0,38-1,52]$} & 0,429 \\
\hline$[5 ; 20]$ & 0,99 & {$[0,53-1,82]$} & 0,967 \\
\hline \multicolumn{4}{|c|}{ Quantidade de quartos } \\
\hline 1 & 1 & & \\
\hline 2 & 1,07 & {$[0,58-1,98]$} & 0,813 \\
\hline 3 a 6 & 0,69 & {$[0,34-1,41]$} & 0,304 \\
\hline \multicolumn{4}{|c|}{ Anos de estudo do chefe da família } \\
\hline$[0 ; 8]$ & 0,77 & {$[0,36-1,64]$} & 0,495 \\
\hline$[9 ; 11]$ & 1,01 & {$[0,44-2,32]$} & 0,973 \\
\hline 12 ou mais & 1,00 & & \\
\hline \multicolumn{4}{|c|}{ Renda do chefe de família } \\
\hline$[0 ; 1]$ & 2,24 & {$[1,06-4,72]$} & 0,036 \\
\hline$[2 ; 3]$ & 1,46 & {$[0,88-2,42]$} & 0,135 \\
\hline 3 ou mais & 1 & & \\
\hline
\end{tabular}




\begin{tabular}{l|c|c|c}
\hline & \multicolumn{3}{|c}{ RSC } \\
\cline { 2 - 4 } & OR & IC 95\% & p-valor \\
\hline Asma diagnosticada por médico & 3,88 & {$[1,94-7,77]$} & 0,001 \\
Sim & 1 & & \\
Não & & & \\
Rinite diagnosticada por médico & 5,02 & {$[3,35-7,53]$} & 0,00 \\
Sim & 1 & & \\
Não & & \\
\hline \hline
\end{tabular}

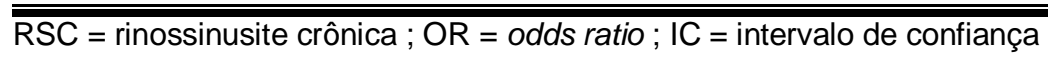

As prevalências de RSC conforme presença ou não de asma [16,47\% (IC 95\% 8,92-28,44) vs. 4,82\% (IC 95\% 3,47-6,67); $\mathrm{p}=0,0001$ )] e de rinite $[15,14 \%$ (IC $95 \% 10,81-20,80$ ) vs. $3,44 \%$ (IC 95\% 2,31-5,09); $\mathrm{p}=0,000$ )] apresentaram uma diferença estatisticamente significativa (Tabela 9). Também foi encontrada associação estatisticamente significativa do diagnóstico de RSC com o diagnóstico de asma (OR 3,88; IC 95\% 1,94-7,77; $p=0,0001)$ e de rinite (OR 5,02; IC 95\% 3,35-7,53; $p=0,0000)$ (Tabela 11).

As prevalências de RSC, segundo o estado tabágico $(p=0,43)$, consumo tabágico em anos $\mathrm{x}$ maço $(\mathrm{p}=0,26)$ e tabagismo passivo intradomiciliar $(p=0,18)$ não apresentaram uma diferença estatisticamente significativa (Tabela 9). Da mesma forma, não foi encontrada uma associação estatisticamente significativa do diagnóstico de RSC segundo estes subgrupos (Tabela 12). 
Tabela 12 - Razão de chances (odds ratio) de rinossinusite crônica, segundo estado tabágico, São Paulo, SP, 2010-2011

\begin{tabular}{l|c|c|c}
\hline \hline & \multicolumn{3}{|c}{ RSC Geral } \\
\cline { 2 - 4 } & OR & IC 95\% & $\mathbf{p}$ \\
\hline Tabagismo & 1 & & \\
$\quad$ Não tabagista & 1,34 & 0,70 & 2,59 \\
$\quad$ Tabagista & 1,39 & 0,80 & 2,43 \\
$\quad$ Ex-tabagista & & & \\
Tabagistas (maços x ano) & 0,98 & 0,43 & 2,25 \\
$\quad$ 1 a 10 & 1,28 & 0,89 & 1,86 \\
$\quad$ 11 ou mais & 1,37 & & 2,19 \\
Tabagismo passivo (no domicílio) & & 0,86 & \\
$\quad$ Sim & 1 & & \\
$\quad$ Não & & & \\
\hline \hline RSC = rinossinusite crônica ; OR = odds ratio ; IC = intervalo de confiança; $\mathrm{p}=$ valor $\mathrm{p}$
\end{tabular}

$\overline{\overline{R S C}}=$ rinossinusite crônica $; \mathrm{OR}=$ odds ratio $; \mathrm{IC}=$ intervalo de confiança; $\mathrm{p}=$ valor $\mathrm{p}$ 
6 DISCUSSÃO 


\section{DISCUSSÃO}

\subsection{Metodologia}

Amostra

Inquéritos populacionais (surveys) produzem estimativas confiáveis, dependendo do rigor metodológico e operacional da estratégia de amostragem. Em surveys, a obtenção de uma amostra representativa da população, utilizando desenho complexo de amostragem e a minimização da quantidade de não respondedores é uma preocupação constante.

A estimativa de prevalência por meio de registros médicos (CID) abrange apenas pacientes que procuram atendimento médico de um determinado centro ou hospital, e podem refletir apenas uma determinada região da cidade atendida por aquela instituição ou uma população não residente na cidade quando avaliada em hospitais terciários.

Os inquéritos populacionais com entrevistas domiciliares objetivam eliminar o viés de amostragem incluindo os pacientes que não tiveram acesso ao atendimento médico, e, assim, aproximando-se de uma amostra representativa da população.

Dentre os principais estudos epidemiológicos, Schiller et al. ${ }^{(13)}$ (2012), Chen et al. ${ }^{(14)}$ (2010), Kim et al. ${ }^{(30)}$ (2011) apresentam um desenho complexo de amostragem, assim como proposto no presente estudo, para obter uma 
amostra representativa da população (Tabela 13). Shashy et al. ${ }^{(15)}$ (2004) utilizaram a codificação internacional (CID-9), porém apresentam a justificativa de escolhê-la, pois trata-se do hospital responsável pelo atendimento de quase a totalidade da população da cidade (Clínica Mayo Rochester, EUA). Hastan et al. ${ }^{(11)}$ (2011) não detalharam o processo de amostragem, citando apenas ter escolhido aleatoriamente pacientes cadastrados nos centros terciários envolvidos na pesquisa (19 centros em 12 países europeus), obtendo uma amostra baseada na população destes locais.

Tabela 13 - Plano de amostragem, critério diagnóstico e taxa de resposta entre os estudos analisados

\begin{tabular}{|c|c|c|c|c|}
\hline Autores & Localização & Amostragem & $\begin{array}{c}\text { Critério } \\
\text { Diagnostico }\end{array}$ & $\begin{array}{c}\text { Taxa de } \\
\text { Resposta } \\
(\%) \\
\end{array}$ \\
\hline $\begin{array}{l}\text { Pilan et al. } \\
(201) \\
(2012)\end{array}$ & São Paulo & $\begin{array}{l}\text { Amostra complexa } \\
\text { Entrevista domiciliar }\end{array}$ & $E P^{3} \mathrm{OS}$ & 87,8 \\
\hline $\begin{array}{l}\text { Hastan et al. }{ }^{(11)} \\
\qquad(2011)\end{array}$ & Europa & $\begin{array}{l}\text { Questionário pelo } \\
\text { correio - escolha } \\
\text { aleatória entre } \\
\text { pacientes cadastrados } \\
\text { em } 19 \text { centros } \\
\text { terciários }\end{array}$ & $E P^{3} \mathrm{OS}$ & $\begin{array}{c}(23,2-80,3) \\
48\end{array}$ \\
\hline Kim et al. ${ }_{(20)}^{(2011)}$ & $\begin{array}{l}\text { Coréia do } \\
\text { Sul }\end{array}$ & $\begin{array}{l}\text { Amostra complexa } \\
\text { Entrevista domiciliar } \\
\text { (médico) }\end{array}$ & $\begin{array}{l}\text { Obstrução nasal e } \\
\text { rinorreia por } \\
3 \text { meses + } \\
\text { endoscopia positiva }\end{array}$ & não publicada \\
\hline $\begin{array}{l}\text { Schiller et al. } \\
\text { (2012) }\end{array}$ & EUA & $\begin{array}{c}\text { Amostra } \\
\text { complexa } \\
\text { Entrevista domiciliar }\end{array}$ & $\begin{array}{l}\text { Doença } \\
\text { autorreferida } \\
\text { (sinusite) }\end{array}$ & 60,8 \\
\hline $\begin{array}{r}\text { Shashy et al. }{ }^{(15)} \\
(2004)\end{array}$ & $\begin{array}{l}\text { Olmsted, } \\
\text { EUA }\end{array}$ & $\begin{array}{c}\text { Amostra de } \\
\text { conveniência } \\
\text { Hospital }\end{array}$ & CID-9 & não se aplica \\
\hline Chen et al. ${ }_{(14)}^{(2003)}$ & Canadá & $\begin{array}{l}\text { Amostra complexa } \\
\text { Entrevista por telefone }\end{array}$ & $\begin{array}{c}\text { Doença } \\
\text { autorreferida } \\
\text { (sinusite) }\end{array}$ & 92,8 \\
\hline
\end{tabular}

CID = Código Internacional de Doenças 


\subsection{Critério diagnóstico}

Existe uma diversidade de metodologias para obtenção dos dados epidemiológicos referentes à prevalência da rinossinusite crônica na literatura, contudo este é o primeiro artigo a estimar a prevalência da RSC segundo os critérios epidemiológicos validados do $\mathrm{EP}^{3} \mathrm{OS}$ obtida por meio de entrevistas domiciliares (face-to-face). Na Europa, Hastan et al. ${ }^{(11)}$ (2011) utilizaram o critério epidemiológico de sintomas do $\mathrm{EP}^{3} \mathrm{OS}$ para determinar a prevalência da RSC, por meio de questionário enviado por correio.

Schiller et al. ${ }^{(13)}$ (2012) e Chen et al. ${ }^{(14)}$ (2003), utilizaram o diagnóstico médico autorreferido, considerando a resposta afirmativa a questão "Você teve sinusite diagnosticada por um profissional de saúde?". Não foi citada a classificação aguda ou crônica na questão. Desta forma, é possível que tenham sido incluídos pacientes com diagnóstico de rinossinusite aguda, ou seja, há o risco de superestimativa do diagnóstico. Este tipo de questão também exclui doentes que não tiveram acesso a atendimento médico. Por outro lado, Chen et al. ${ }^{(14)}$ (2003), apesar de utilizar a mesma questão, destacaram no início de seu questionário para abordagem de múltiplas doenças, que fossem respondidas afirmativamente apenas as doenças que apresentaram sintomas por mais de seis meses, com o intuito de excluir pacientes com doença aguda.

Um fato importante a ser ressaltado é que no Brasil a resposta negativa à pergunta "Durante os últimos 12 meses, você teve o diagnóstico 
de sinusite dado por um médico?" poderia significar que a pessoa não teve o diagnóstico realizado por não ter procurado um médico ou porque não teve a oportunidade de ser atendida por um médico. A resposta afirmativa também poderia resultar em uma prevalência superestimada pela inclusão de pacientes com diagnóstico de rinossinusite aguda (bacteriana ou viral) porque o diagnóstico médico foi realizado em serviços de prontoatendimento ou por médico não especialista que não dispõe da endoscopia nasal e que, em geral, também não realiza rinoscopia anterior. No presente estudo obteve-se $16,55 \%$ de diagnóstico autorreferido utilizando a mesma questão sem especificar doença aguda ou crônica no questionamento, e observou-se uma quantidade expressiva de pacientes $(45,6 \%)$ que não sabiam informar se a rinossinusite era aguda ou crônica dentre os que responderam ter um diagnóstico médico de sinusite. Esta informação é um reflexo da falta de uma orientação detalhada do médico, após o diagnóstico da doença ou do desinteresse do paciente sobre o caráter agudo ou crônico da mesma.

A obtenção dos dados em entrevistas domiciliares também permite uma maior confiabilidade nas repostas e um maior detalhamento das informações, o que provavelmente não seria tão eficaz com aplicação de um questionário de auto preenchimento enviado pelo correio, como o utilizado por Hastan et al. ${ }^{(11)}(2011)$.

Kim et al. ${ }^{(30)}(2011)$ utilizaram como critério diagnóstico os sintomas de obstrução nasal e rinorreia por mais de três meses associados à 
endoscopia nasal positiva (presença de secreção, edema ou pólipos em meato médio), sendo a entrevista e exame realizados por médico otorrinolaringologista. Esta pesquisa apresenta o critério diagnóstico mais específico dentre os estudos epidemiológicos, pois a presença destes sintomas e endoscopia positiva se enquadrariam no diagnóstico clínico estabelecido pelo $\mathrm{EP}^{3} \mathrm{OS}$.

Shashy et al. ${ }^{(15)}$ (2004) utilizaram o Código Internacional de Doenças (CID-9) para determinar a prevalência da RSC, e como critério diagnóstico, precisa-se estar certo que não houve falha no preenchimento médico, o que pode ocorrer, mesmo sem intenção, por erro diagnóstico e que nos pacientes com múltiplas doenças também foi incluído o CID de RSC se esta estivesse presente. Além disso, $70 \%$ dos diagnósticos foram dados por médicos de família ou por clínicos gerais e apenas $8 \%$ pelo departamento de Otorrinolaringologia desta instituição.

\subsection{Taxa de resposta}

Em surveys, a minimização da quantidade de não respondedores é um fator crucial para a inferência estatística correta. A busca ativa de sujeitos por entrevista domiciliar, apesar de mais custosa, é uma forma de avaliação de prevalência com menor chance de vieses. No presente estudo obteve-se taxa de resposta acima do esperado $(87,8 \%)$ para uma cidade 
como São Paulo, que seria considerado um bom resultado se estivesse próxima de $80 \%$.

Entrevistas por correspondência podem ter viés de amostragem, pois indivíduos sintomáticos podem ser mais propensos a responder 0 questionário. Hastan et al. ${ }^{(11)}$ (2011), utilizaram questionários de autopreenchimento enviados por correio. Caso não houvesse resposta em três meses um novo questionário seria enviado. Entretanto, não há detalhes sobre o perfil dos não respondedores. Apenas em oito centros havia informação sobre o gênero e idade dos não respondedores, mas sem informação sobre os sintomas nasais ou outros diagnósticos. Além disso, houve grande variabilidade da taxa de resposta entre os centros $(23,2 \%$ $80,3 \%$ e foi considerada a taxa de resposta total de $48 \%$ que envolvia todos os centros. (Tabela 13)

Entre os inquéritos com desenho de amostragem complexo e diagnóstico autorreferido, Schiller et al. ${ }^{(13)}$ (2012) obtiveram taxa de resposta de $60,8 \%$ e Chen et al. ${ }^{(14)}$ (2003) de 92,8\%. Kim et al. ${ }^{(30)}$ (2011) não publicaram a taxa de resposta encontrada.

\subsection{Prevalência}

Sem dúvida o diagnóstico epidemiológico apresenta limitações quando é comparado com o diagnóstico clínico na prática médica. A anamnese realizada por médico, os achados endoscópicos ou as alterações 
na TC são parte essencial para o diagnóstico clínico. Os custos altos e os problemas logísticos implicados na confirmação clínica do diagnóstico de RSC tornam a sua realização inviável em uma pesquisa epidemiológica. Além disso, um estudo epidemiológico adequado pode inferir a prevalência da doença e trazer informações relevantes sobre a doença.

Considerando todas as limitações encontradas entre os estudos epidemiológicos mais importantes publicados na literatura, encontrou-se uma prevalência entre $2 \%$ e $13 \%$, e esta discrepância pode refletir a falta de uniformidade na metodologia dos estudos. (Tabela 14)

Tabela 14 - Características da amostra e prevalência de RSC entre os trabalhos analisados

\begin{tabular}{|c|c|c|c|c|}
\hline Autores & $\begin{array}{c}\text { Localização / } \\
\text { Ano do inquérito }\end{array}$ & População & n; idade & $\begin{array}{c}\text { Prevalência } \\
(\%)\end{array}$ \\
\hline $\begin{array}{l}\text { Pilan et al. } \\
\qquad(201) \\
(2012)\end{array}$ & $\begin{array}{l}\text { São Paulo / } \\
2010-2011\end{array}$ & $\begin{array}{c}1 \text { cidade } \\
11 \text { milhões de } \\
\text { habitantes }\end{array}$ & $\begin{aligned} & 2.003 \\
\geq & 12 \text { anos }\end{aligned}$ & 5,51 \\
\hline $\begin{array}{l}\text { Hastan et al. } \\
\qquad(2011)\end{array}$ & $\begin{array}{l}\text { Europa / } \\
12 \text { países } \\
19 \text { centros } \\
\text { terciários } \\
2008\end{array}$ & $\begin{array}{l}12 \text { países europeus / } \\
19 \text { centros terciários }\end{array}$ & $\begin{array}{c}57.128 ; \\
15 \text { a } 75 \text { anos }\end{array}$ & $\begin{array}{c}10,9 \\
(6,9-27,1)\end{array}$ \\
\hline Kim et al. ${ }_{(20)}^{(2011)}$ & $\begin{array}{l}\text { Coréia do Sul / } \\
2008\end{array}$ & $\begin{array}{l}\text { Amostra nacional } \\
48 \text { milhões de } \\
\text { habitantes }\end{array}$ & $\begin{array}{c}4.098 \\
\geq 12 \text { anos }\end{array}$ & 6,95 \\
\hline $\begin{array}{r}\text { Schiller et al. } \\
(2012)\end{array}$ & EUA / 2010 & Amostra nacional & $\begin{array}{l}27.157 ; \\
\geq 18 \text { anos }\end{array}$ & 13 \\
\hline $\begin{array}{r}\text { Shashy et al. } \\
(2004)\end{array}$ & $\begin{array}{c}\text { Olmsted, EUA / } \\
2000\end{array}$ & $\begin{array}{c}\text { Condado (Cidade de } \\
\text { Rochester }+ \\
13 \text { cidades satélites) } \\
124 \text { mil habitantes }\end{array}$ & $\begin{array}{l}2.405 ; \\
4 \text { meses a } \\
94 \text { anos }\end{array}$ & 1,96 \\
\hline $\begin{array}{l}\text { Chen et al. }{ }^{(14)} \\
(2003)\end{array}$ & $\begin{array}{l}\text { Canadá / } \\
\text { 1996-1997 }\end{array}$ & $\begin{array}{l}\text { Amostra nacional } \\
29 \text { milhões de } \\
\text { habitantes }\end{array}$ & $\begin{array}{l}73.364 \\
\geq 12 \text { anos }\end{array}$ & $\begin{array}{l}3,4 \% \text { de } \\
\text { homens, } \\
5,7 \% \text { de } \\
\text { mulheres }\end{array}$ \\
\hline
\end{tabular}

$\mathrm{n}$ = quantidade de pessoas; \% porcento 
A prevalência encontrada no presente estudo (5,51\%; IC 95\% 3,99$7,58)$ foi menor do que a publicada recentemente no estudo GA ${ }^{3} \mathrm{LEN}$ $(10,9 \% \text {; IC 95\% 6,9-27,1 })^{(11)}$, o qual utiliza o mesmo critério diagnóstico, sendo encontrada associação com o gênero feminino (OR 1,08; IC 95\% 1,02 $-1,15 ; p=0,16)$. Apesar dos dados deste estudo serem baseados na análise dos mesmos sintomas, foram obtidos por meio de questionários enviados por correio. Houve grande variação entre as taxas de resposta de cada centro deste estudo $(23,2 \%$ a $80,3 \%)$, e não foram reportadas as característica dos não respondedores. Sempre é possível que haja maior estímulo e interesse em responder à pesquisa quando o entrevistado tem a doença ou os sintomas questionados. Hipóteses para esta diferença de prevalência entre o presente estudo e o estudo $G A^{2} L E N$, pode ser a variação das características geográficas, das características da população estudada e reflexo da menor taxa de resposta (amostra selecionada?).

Os resultados aqui apresentados assemelham-se à prevalência da RSC em canadenses em aproximadamente 5\% (gênero feminino 3,4\% vs. gênero masculino 5,7\%). Chen et al. ${ }^{(14)}$ (2003) obtiveram uma amostra representativa da população e uma alta taxa de resposta. Utilizaram o diagnóstico médico autorreferido de RSC e ao iniciar orientavam o entrevistado que a pesquisa se limitava a perguntas sobre doenças crônicas com sintomas de duração superior a seis meses. A duração dos sintomas avaliados por Chen et al. ${ }^{(14)}$ foi maior do que a sugerida pelo EP ${ }^{3} \mathrm{OS}$ (três meses), o que pode ter subestimado a prevalência desta doença segundo este critério. 
No presente estudo foi incluída a questão sobre o diagnóstico médico autorreferido, da mesma forma como é realizada na população americana. A prevalência de RSC autorreferida encontrada em São Paulo (16,55\%) foi maior do que da população americana, publicada pelo National Center of Health Statistics de $2012(13 \%)^{(13)}$. No presente estudo, a diferença entre a prevalência obtida pelo critério epidemiológico $E P^{3} O S$ e o diagnóstico autorreferido (5,51\% vs. $16,55 \%)$ possivelmente representa a inclusão de casos agudos no diagnóstico médico autorreferido. Ainda, considerando a população estadunidense, Shashy et al ${ }^{(15)}$ (2004) obtiveram prevalência de $2 \%$, utilizando o diagnóstico por CID obtido em hospital que atende a quase totalidade da população da cidade, havendo muita discrepância com o valor obtido no inquérito domiciliar no mesmo país (13\%), mesmo considerando perdas de indivíduos com RSC que não procuraram auxílio médico.

Kim et al ${ }^{(30)}$ (2011), na Coréia do Sul, utilizaram o melhor critério diagnóstico, com a entrevista feita por otorrinolaringologista associado a realização de endoscopia nasal, e pela metodologia descrita apresentavam uma amostra representativa da população, obtendo prevalência de 6,95\% de RSC, valor próximo ao encontrado no presente estudo, sendo a prevalência maior em homens (8,24\% vs. $6,00 \%)$.

Os inquéritos domiciliares são ferramentas valiosas para a obtenção de informação e monitoração da saúde da população, entretanto sua realização têm custo alto, por isso, geralmente são pesquisadas múltiplas doenças crônicas na mesma entrevista, o que difere do objetivo do inquérito 
do presente estudo que foi direcionado apenas para rinossinusite. $O$ diagnóstico médico autorreferido utiliza uma questão simples ("Você tem o diagnóstico de sinusite feito por um médico?"), que é facilmente reprodutível, e pode ser comparada em pesquisas subsequentes ou entre populações, e traduz um dado importante da repercussão da rinossinusite na sociedade. Porém, como existe a subclassificação de rinossinusite aguda ou crônica, diferentemente de outras doenças crônicas como hipertensão arterial ou diabetes, torna-se um fator de confusão e, do ponto de vista da pesquisadora, este dado não pode ser considerado como prevalência de RSC e sim de rinossinusite, doença aguda e crônica pela falta de especificidade da questão por não assegurar que os sintomas duraram mais de três meses.

\subsection{RSC e Asma}

Schiller et al. ${ }^{(13)}(2012)$ e Shashy et al. ${ }^{(15)}$ (2004) não pesquisaram diagnóstico de asma como fator associado à RSC em suas pesquisas epidemiológicas. Kim et al. ${ }^{(30)}$ (2011) não encontraram associação entre presença de asma e RSC (OR 1,91; IC 95\% 0,80-4,55; $p=0,143$ ).

Chen et al. ${ }^{(14)}$ (2003) encontraram prevalência de RSC duas a três vezes maior em indivíduos asmáticos do que em não asmáticos (homens: OR 7,4\%; IC 95\% 5,4-9,4 vs. 3,2\%; IC 95\% 2,7-3,7; mulheres OR 11,5\%; IC 95\% 9,7-13,3 vs. OR 5,1\%; IC 95\% 4,7-5,6) e a associação caracterizada 
pelo OR 1,94, IC 95\%: 1,24-3,03 para homens e OR 1,73; IC 95\% 1,36-2,20 para mulheres (Tabela 15).

Tabela 15 - Razão de chances (odds ratio) de rinossinusite crônica e presença de asma, entre os estudos analisados

\begin{tabular}{|c|c|}
\hline Autores & OR RSC vs. Asma \\
\hline Chen et al. ${ }^{(14)}$ & Homens: OR 1,94; IC 95\% 1,24-3,03 \\
\hline$(2003)$ & Mulheres: OR 1,73; IC 95\% 1,36-2,20 \\
\hline 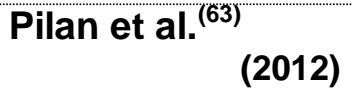 & OR 3,88; IC 95\% 1,94- 7,77 \\
\hline Jarvis et al. ${ }^{(33)}$ & OR 3,48; IC 95\% 3,21-3,77 \\
\hline Kim et al. ${ }^{(30)}$ & OR 1,$91 ;$ IC $95 \% 0,80-4,55 ; p=0,143$ \\
\hline
\end{tabular}

$\overline{\mathrm{OR}}=$ odds ratio; $\mathrm{RSC}$ = rinossinusite crônica; IC = intervalo de confiança; $\mathrm{p}=\mathrm{p}$-valor

Hastan et al. ${ }^{(11)}$ (2011) também não pesquisaram associação com asma em sua publicação, porém o estudo GA²LEN (Global Allergy and Asthma Network of Excellence) em publicação de Jarvis et al. ${ }^{\left({ }^{(3)}\right.}$ (2012), com análise de outros dados dos mesmos questionários e com a mesma metodologia, encontraram uma forte associação entre o diagnóstico de asma e RSC (OR 3,48; IC 95\%: 3,21-3,77). A associação com asma foi ainda maior quando ambas, a RSC e a rinite alérgica, eram reportadas (OR 11,85; IC $95 \% 10,57-13,17)$. No presente estudo a prevalência de RSC em pacientes com asma autorreferida diagnosticada por um médico foi significativamente maior do que nos pacientes sem esta doença com uma associação importante (OR 3,88; IC 95\% 1,94-7,77\%). 
As evidências científicas sugerem que a inflamação coexiste nas vias aéreas superiores e inferiores, e devem ser consideradas como um continuum ${ }^{(39)}$, sendo importante uma abordagem integrada das duas doenças para se instituir uma terapêutica adequada. Contudo, mais ensaios clínicos são necessários para comprovar que o tratamento da rinossinusite melhore os sintomas de asma.

\subsection{RSC e Rinite}

Há uma grande dificuldade em realizar comparações entre os estudos epidemiológicos pela diversidade de critérios diagnósticos utilizados para rinite / alergia. Na maioria dos estudos epidemiológicos não houve realização de exame físico e nenhum deles utilizou exames específicos para comprovar a reação IgE mediada, e a maioria dos diagnósticos foi baseada nos sintomas e em diagnósticos médicos autorreferidos.

Chen et al. ${ }^{(14)}$ (2003) encontraram forte associação de RSC e diagnóstico médico autorreferido de alergia. Kim et al. ${ }^{(30)}(2011)$ encontraram associação entre RSC e rinite apenas quando a rinite foi classificada pela frequência e gravidade segundo os critérios da iniciativa $\operatorname{ARIA}^{(64)}$ e a associação presente apenas na rinite persistente (leve ou moderadasevera). (Tabela 16) 
Tabela 16 - Razão de chances (odds ratio) de rinossinusite crônica e presença de rinite, entre os estudos analisados

\begin{tabular}{|c|c|c|c|}
\hline Autores & \multicolumn{2}{|c|}{ OR RSC e Rinite } & $\begin{array}{c}\text { Critério diagnóstico } \\
\text { da rinite }\end{array}$ \\
\hline 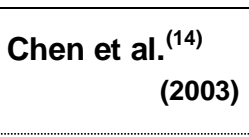 & \multicolumn{2}{|c|}{$\begin{array}{l}\text { Homens: OR 3,46; IC 95\%: 2,57-4,65 } \\
\text { Mulheres: OR 3,30; IC 95\%: 2,77-3,94 }\end{array}$} & $\begin{array}{l}\text { Diagnóstico médico } \\
\text { autorreferido de alergias } \\
\text { (incluindo alimentar) }\end{array}$ \\
\hline $\begin{array}{l}\text { Pilan et al. } \\
\qquad(2012)\end{array}$ & \multicolumn{2}{|c|}{$\begin{array}{l}\text { OR 5,02; IC 95\%: 3;35-7;53 } \\
\text { 50,9\% (53/104) dos indivíduos com RSC e } \\
\text { diagnóstico medico autorreferido de rinite }\end{array}$} & $\begin{array}{l}\text { Diagnóstico médico } \\
\text { autorreferido de rinite }\end{array}$ \\
\hline $\begin{array}{l}\text { GA }^{2} \text { LEN } \\
\text { Hastan et al. }{ }^{(11)} \\
\text { Jarvis et al. }{ }_{(33)}^{(2011)} \\
(2012)\end{array}$ & \multicolumn{2}{|c|}{$\begin{array}{l}56,7 \% \text { dos indivíduos com RSC reportaram } \\
\text { sintomas alérgicos nasais } \\
\text { RSC + Rinite + Asma OR 11,85; IC 95\% 10,57-13,1 }\end{array}$} & Diagnóstico autorreferido \\
\hline & \multicolumn{2}{|c|}{ OR 1,$38 ;$ IC $95 \% 0,87-2,21 ; p=0,16$} & Rinite alérgica segundo \\
\hline Kim et al. ${ }_{(2011)}^{(201)}$ & $\begin{array}{l}\text { RA intermitente leve } \\
\text { RA intermitente mod.-severa } \\
\text { RA persistente leve } \\
\text { RA persistente mod.-severa }\end{array}$ & $\begin{array}{l}\text { OR } 1 \\
\text { OR } 1,61 ; p=0,13 \\
\text { OR } 2,57 ; p=0,006^{*} \\
\text { OR } 8,20 ; p=0,000^{*}\end{array}$ & $\begin{array}{l}\text { ARIA (sintomas + exame } \\
\text { físico) sem realização de } \\
\text { testes alérgicos }\end{array}$ \\
\hline
\end{tabular}

$\overline{\mathrm{OR}}=$ odds ratio; $\mathrm{RSC}$ = rinossinusite crônica; $\mathrm{RA}=$ rinite alérgica; $\mathrm{IC}$ = intervalo de confiança; $\mathrm{p}$ = $\mathrm{p}$-valor; mod. = moderada

Hastan et al. ${ }^{(11)}$ (2011) não descreveram a associação RSC e rinite em seu estudo, porém Jarvis et al. ${ }^{(33)}$ (2012), utilizando a mesma amostra do estudo GA $^{2}$ LEN em seu artigo com enfoque em asma, relataram que $56,7 \%$ dos pacientes que preencheram critério epidemiológico para RSC reportaram sintomas alérgicos nasais.

No presente estudo, a prevalência de RSC em pacientes com rinite autorreferida foi significativamente maior do que em pacientes sem esta doença com uma associação importante (OR 5,02; IC 95\% 3,35-7,53), e $50,9 \%$ (53/104) dos pacientes com diagnóstico de RSC reportaram rinite diagnosticada por médico. 
Embora artigos de revisão sugiram que a alergia predispõe à rinossinusite e os artigos publicados, inclusive epidemiológicos, reportem uma prevalência alta de alergia neste grupo de pacientes citando-a como um fator associado, e que atua como um gatilho ou fator exacerbador da doença, não existe uma forte evidência para uma relação causal clara entre rinite alérgica e rinossinusite crônica ${ }^{(47-49,65,66)}$, entretanto considera-se fundamental o diagnóstico e tratamento da rinite em pacientes com RSC.

\subsection{RSC e Tabagismo}

No presente estudo o tabagismo não foi mais prevalente na população com rinossinusite crônica $(17,30 \%)$ em relação à população geral e não houve associação entre RSC e tabagismo (OR 1,34; IC 95\% 0,702,59) na amostra estudada, mesmo quando foi feita análise separadamente por gênero. Uma das hipóteses por não ter sido encontrada esta associação é que a prevalência de tabagistas na população adulta $\geq 18$ anos de São Paulo foi estimada em 20\%, segundo dados do VIGITEL ${ }^{(67)}$ (2010) um inquérito populacional por telefone e no presente estudo foi encontrada uma prevalência de tabagistas na população com idade $\geq 12$ anos de $16,23 \%$ (IC 95\% 13,2-19,2). Esta taxa menor de prevalência pode ter influenciado os dados obtidos.

Na Europa houve forte associação entre RSC e tabagismo (OR 1,91; IC 95\% 1,77-1,05) ${ }^{(11)}$. (Tabela 17) 
Tabela 17 - Razão de chances (odds ratio) de rinossinusite crônica e estado tabágico entre os estudos analisados

\begin{tabular}{|c|c|c|}
\hline Autores & OR RSC e tabagismo & $\begin{array}{c}\text { OR RSC e } \\
\text { tabagismo passivo }\end{array}$ \\
\hline $\begin{array}{r}\text { Chen et al. }^{(14)} \\
\\
\text { (2003) }\end{array}$ & $\begin{array}{l}\text { Mulheres: OR 1,57; IC 95\%: 1,24-1,99 } \\
\text { Homens: OR 1,24; IC 95\%: 0,90-1,70 }\end{array}$ & Não investigado \\
\hline $\begin{array}{l}\text { Hastan et al. }{ }^{(11)} \\
\text { (2011) }\end{array}$ & OR 1,$91 ;$ IC $95 \%$ 1,77-1,05 & Não investigado \\
\hline Kim et al. ${ }^{(30)}$ & $\begin{array}{l}\text { Não houve associação (Dados estatísticos } \\
\text { não publicados, apenas comentados na } \\
\text { discussão) }\end{array}$ & Não investigado \\
\hline $\begin{array}{l}\text { Pilan et al. }{ }^{(63)} \\
\qquad(2012)\end{array}$ & OR 1,34; IC 95\% 0,70-2,59 & OR 1,$37 ;$ IC $95 \% 0,86-2,19$ \\
\hline
\end{tabular}

OR = odds ratio; $\mathrm{RSC}$ = rinossinusite crônica; $\mathrm{IC}$ = intervalo de confiança

Chen et al. ${ }^{(14)}$ (2003) encontraram associação significativa entre rinossinusite crônica e mulheres tabagistas (OR 1,57; IC 95\% 1,24-1,99), porém, não foi encontrada associação com homens tabagistas (OR 1,24; IC $95 \%$ 0,90-1,70).

Kim et al. ${ }^{(30)}$ (2011) obtiveram uma porcentagem de $47,7 \%$ de homens tabagistas em sua amostra, em comparação com $7,3 \%$ de mulheres e a prevalência de RSC entre os homens foi maior que em mulheres $(8,24 \%$ vs. $6 \% ; \mathrm{p}=0,005)$, entretanto, de maneira geral, o tabagismo não se caracterizou como fator de risco em sua população.

Um aumento da prevalência de RSC em tabagistas por causa de todas as evidências científicas do seu malefício para as vias aéreas, embora fosse esperado não se confirmou e os dados encontrados em estudos epidemiológicos ainda se mostram conflitantes. Provavelmente deve haver características individuais que estejam associadas ao diagnóstico de RSC 
em tabagistas e um questionamento mais detalhado sobre quantidade de cigarros, presença de alergia e outros fatores pudessem trazer mais informações para estabelecer esta associação ou relação causal em estudos futuros.

\subsection{RSC e Fatores socioeconômicos}

Chen et al. ${ }^{(14)}$ (2003) não encontraram associação entre presença de RSC e escolaridade baixa (OR 0,88; IC 95\% 0,68-1,15 em homens e OR 0,83; IC 95\% 0,70-1,00 em mulheres). Da mesma forma, Kim et al ${ }^{(30)}$ (2011), não observaram esta associação (OR 1,35; IC 95\% 0,96-1,91) assim como no presente estudo (OR 0,77; IC 95\% 0,36-1,64).

Fatores econômicos observados por Kim et al. ${ }^{(30)}(2011)$ na Coréia do Sul, não mostram uma associação de renda baixa e presença de RSC (OR 0,86; IC 95\% 0,67-1,11). (Tabela 18)

Tabela 18 - Razão de chances (odds ratio) de rinossinusite crônica e características econômicas entre os estudos analisados

\begin{tabular}{l|l}
\hline \hline Autores & \multicolumn{1}{c}{ OR RSC e baixa renda } \\
\hline Chen et al. ${ }^{(14)}(\mathbf{2 0 0 3 )}$ & Mulheres: OR 1,37; IC 95\% 1,05-1,79 \\
& Homens: OR 2,06; IC 95\% 1,30-3,27 \\
\hline Kim et al. ${ }^{(30)}(\mathbf{2 0 1 1 )}$ & Não houve associação OR 0,86 IC 95\% 0,67-1,11 p=0,2 \\
\hline Pilan et al. ${ }^{(63)}$ (2012) & OR 2,24; IC 95\% 1,06-4,72, p=0,036 \\
\hline \hline OR = odds ratio; RSC = rinossinusite crônica; IC = intervalo de confiança
\end{tabular}

$\overline{\mathrm{OR}}=$ odds ratio; $\mathrm{RSC}$ = rinossinusite crônica; IC = intervalo de confiança 
Chen et al. ${ }^{(14)}$ (2003), no Canadá, obtiveram associação de RSC e renda baixa (OR 2,06; IC 95\% 1,30-3,27 em homens e OR 1,37; IC 95\% 1,05-1,79 em mulheres).

No presente estudo o subgrupo de renda mensal do chefe de família apresentou uma diferença tendendo à significância estatística $(p=0,0677)$. Este $p$ marginalmente significativo pode traduzir alguma tendência a, de fato, haver uma maior prevalência de RSC nessa faixa de renda da população. Isto foi confirmado com uma associação estatisticamente significativa entre a presença desta doença e o subgrupo de renda baixa (OR 2,24; IC 95\% 1,06$4,72 ; p=0,036)$.

Estes resultados não permitem explicar qual a relação causal da associação, porém pode-se supor a dificuldade de acesso ao atendimento médico ou dificuldade em adquirir medicamentos como explicações. 
7 CONCLUSÃO 


\section{CONCLUSÃO}

O inquérito populacional sobre rinossinusite crônica na população da cidade de São Paulo permitiu estimar a prevalência de RSC em 5,51\% da população com idade de 12 anos ou mais. Os fatores associados à RSC encontrados foram asma, rinite e renda baixa. Não houve associação de RSC com tabagismo e escolaridade. 
ANEXOS 


\section{ANEXO A}

\section{RELAÇÃO DOS SETORES SORTEADOS DO MUNICÍPIO DE SÃO PAULO}

\begin{tabular}{|c|c|c|}
\hline Distrito & $\begin{array}{c}\text { Código } \\
\text { identificação }\end{array}$ & Domicílios \\
\hline Alto de Pinheiros & 355030802000002 & 160 \\
\hline Brasilândia & 355030811000056 & 211 \\
\hline Brasilândia & 355030811000087 & 246 \\
\hline Brasilândia & 355030811000143 & 369 \\
\hline Campo Belo & 355030815000002 & 316 \\
\hline Campo Belo & 355030815000094 & 124 \\
\hline Casa Verde & 355030821000051 & 234 \\
\hline Cidade Ademar & 355030822000044 & 240 \\
\hline Cidade Ademar & 355030822000050 & 385 \\
\hline Cidade Ademar & 355030822000094 & 217 \\
\hline Cidade Ademar & 355030822000095 & 255 \\
\hline Cidade Dutra & 355030823000009 & 239 \\
\hline Cidade Líder & 355030824000087 & 156 \\
\hline Ermelino Matarazzo & 355030828000058 & 222 \\
\hline Grajaú & 355030830000271 & 225 \\
\hline Itaim Bibi & 355030835000132 & 309 \\
\hline Itaim Paulista & 355030836000238 & 150 \\
\hline Itaquera & 355030837000129 & 247 \\
\hline Jabaquara & 355030838000067 & 230 \\
\hline Jabaquara & 355030838000212 & 329 \\
\hline Jaraguá & 355030842000019 & 383 \\
\hline Jardim Angela & 355030843000255 & 278 \\
\hline Jardim Helena & 355030844000136 & 365 \\
\hline Jardim Paulista & 355030845000038 & 321 \\
\hline Jardim Paulista & 355030845000163 & 263 \\
\hline Jardim São Luiz & 355030846000295 & 283 \\
\hline Mandaqui & 355030851000094 & 295 \\
\hline Parelheiros & 355030855000067 & 324 \\
\hline Parque do Carmo & 355030857000025 & 283 \\
\hline Pedreira & 355030858000132 & 185 \\
\hline
\end{tabular}


Continuação - Relação dos setores sorteados do Município de São Paulo

\begin{tabular}{l|c|c}
\hline \hline Distrito & $\begin{array}{c}\text { Código } \\
\text { identificação }\end{array}$ & Domicílios \\
\hline Perus & 355030861000029 & 357 \\
Perus & 355030861000031 & 322 \\
República & 355030866000054 & 134 \\
República & 355030866000055 & 241 \\
Rio Pequeno & 355030867000024 & 206 \\
Sacomã & 355030868000249 & 368 \\
Santana & 355030870000082 & 213 \\
Santana & 355030870000129 & 263 \\
São Lucas & 355030872000103 & 276 \\
São Mateus & 355030873000036 & 208 \\
São Rafael & 355030875000133 & 135 \\
Sapopemba & 355030876000035 & 229 \\
Sé & 355030878000022 & 241 \\
Tatuapé & 355030880000071 & 276 \\
Tucuruvi & 355030882000011 & 376 \\
Tucuruvi & 355030882000049 & 177 \\
Vila Andrade & 355030883000050 & 343 \\
Vila Formosa & 355030885000010 & 196 \\
Vila Guilherme & 355030886000034 & 275 \\
Vila Sonia & 355030894000005 & 172 \\
\hline \hline
\end{tabular}


ANEXO B
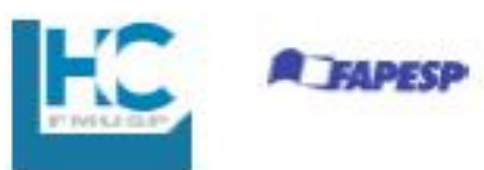

Fundoçao

Otarinolaringologia

\section{PROJETO SINUSITE}

\section{RELAÇÃO DOS MORADORES DOS DOMICÍLIOS SORTEADOS}

BLOCO A

Telefone:

\begin{tabular}{|c|c|c|c|c|c|c|}
\hline VISITA & DATA & HORA & $\begin{array}{l}\text { NOME DO } \\
\text { ENTREVISTADOR }\end{array}$ & OBSERVAÇÕES & $\begin{array}{l}\text { RESULTADO } \\
\text { DA VISITA }\end{array}$ & $\begin{array}{l}\text { 1- REALIZADA } \\
2 \text {-NÁO PERTENCE } \dot{A} \\
\text { POPULAÇÃO EM } \\
\text { ESTUDO }\end{array}$ \\
\hline 1 & 1 & & & & & $\begin{array}{l}3 \text {-NÚMERO } \\
\text { EXISTENTE }\end{array}$ \\
\hline 2 & 1 & & & & & $\begin{array}{l}\text { 4- DOMICÍLIO } \\
\text { FECHADO }\end{array}$ \\
\hline 3 & 1 & & & & & $\begin{array}{l}5 \text { - NAOO E DOMICILIO } \\
6 \text { - RECUSA }\end{array}$ \\
\hline 4 & 1 & & & & & $\begin{array}{l}\text { 7- DOMICILIO VAGO } \\
\text { - OUTROS, ESPECIF }\end{array}$ \\
\hline 5 & 1 & & & & & \\
\hline 6 & 1 & & & & & \\
\hline
\end{tabular}

A 03. RESULTADOS DAS VISITAS

A 04. $N^{\circ}$ DE VISITAS:

A 05. ENTREVISTADOS

A 06. DATA DO PREENCHIMENTO DO QUADRO DE MORADORES

................................

Obs: 
A 07. NÚMERO DE FAMÍLIAS NO DOMICÍLIO:

\section{A 08. QUADRO DE MORADORES NO DOMICÍLIO:}

\begin{tabular}{|c|c|c|c|c|c|c|c|c|c|}
\hline & \multirow[b]{2}{*}{$\mathbf{N}^{\circ}$} & \multirow[b]{2}{*}{ NOME } & \multirow{2}{*}{$\begin{array}{c}\text { IDADE } \\
\text { Se menor } \\
\text { anotar } 000\end{array}$} & \multicolumn{2}{|c|}{ SEXO } & \multirow{2}{*}{$\begin{array}{l}\text { RELACCAOO } \\
\text { PARENTESCO } \\
\text { COM CHEFE } \\
\end{array}$} & \multirow{2}{*}{$\begin{array}{c}\text { Marque com X } X \\
\text { o morador que } \\
\text { foi sorteado }\end{array}$} & \multirow{2}{*}{$\begin{array}{c}\mathrm{N}^{\circ} \mathrm{DE} \\
\text { ORDEM }\end{array}$} & \multirow[b]{2}{*}{ Resultado } \\
\hline & & & & M & $\mathrm{F}$ & & & & \\
\hline A 08a & & & & 1 & 2 & & & & \\
\hline A 08b & & & & 1 & 2 & & & & \\
\hline A 08c & & & & 1 & 2 & & & & \\
\hline A 08d & & & & 1 & 2 & & & & \\
\hline A 08e & & & & 1 & 2 & & & & \\
\hline A $08 f$ & & & & 1 & 2 & & & & \\
\hline A 08g & & & & 1 & 2 & & & & \\
\hline A 08i & & & & 1 & 2 & & & & \\
\hline A 08j & & & & 1 & 2 & & & & \\
\hline A 08k & & & & 1 & 2 & & & & \\
\hline A 081 & & & & 1 & 2 & & & & \\
\hline A 08m & & & & 1 & 2 & & & & \\
\hline A 08n & & & & 1 & 2 & & & & \\
\hline A 080 & & & & 1 & 2 & & & & \\
\hline A 08p & & & & 1 & 2 & & & & \\
\hline A 08q & & & & 1 & 2 & & & & \\
\hline A 08r & & & & 1 & 2 & & & & \\
\hline A 08s & & & & 1 & 2 & & & & \\
\hline A 08t & & & & 1 & 2 & & & & \\
\hline & & & & & & $\begin{array}{l}\text { Relação parente } \\
\text { 02. cônjuge } \\
\text { 03. filho/enteado } \\
\text { 04. pai/mãe/sogro } \\
\text { 05. neto/bisneto } \\
\text { 06. irmão/imã } \\
\text { 07. outro parente } \\
\text { 08. agregado } \\
\text { 09. pensionista } \\
\text { 10. empregado do } \\
\text { 11. parente do em } \\
\text { 12. outro: ........... }\end{array}$ & $\begin{array}{l}\text { com o chefe: } \\
\text { éstico } \\
\text { egado doméstico }\end{array}$ & $\begin{array}{l}\text { Resultad } \\
\text { 1. Realiz } \\
\text { 2. Ageno } \\
\text { 3. Ausen } \\
\text { 4. Recus } \\
\text { 5. Impos } \\
\text { respor }\end{array}$ & $\begin{array}{l}\text { a } \\
\text { da } \\
\text { ilidade de } \\
\text { er }\end{array}$ \\
\hline
\end{tabular}




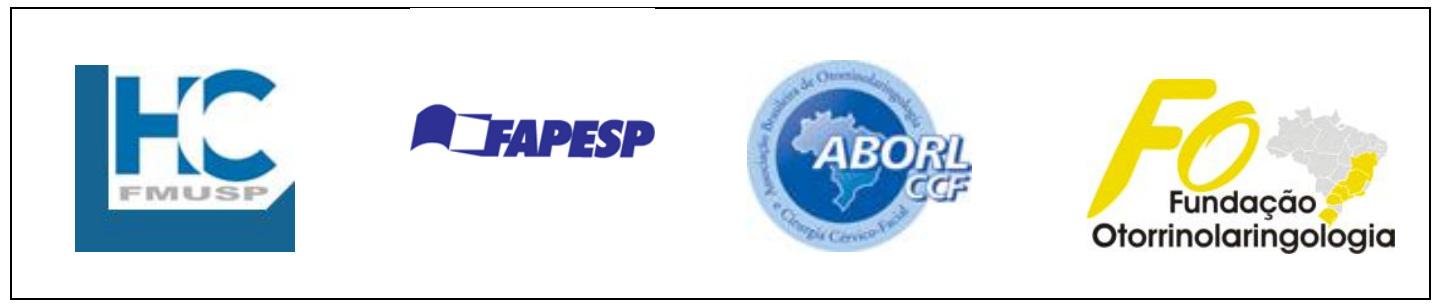

PROJETO RINOSSINUSITE

BLOCO B

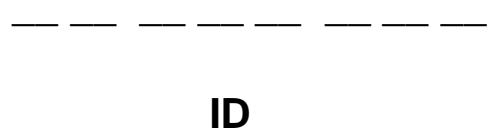

№ da família

№ de ordem

END.:

$\mathrm{N}^{\mathrm{O}}$ :

COMPL.:

E-MAIL:

TEL.:

NOME COMPLETO DO (A) ENTREVISTADO (A):

\begin{tabular}{|c|c|c|c|c|c|c|}
\hline VISITA & DATA & HORA & $\begin{array}{c}\text { NOME DO } \\
\text { ENTREVISTADOR }\end{array}$ & OBSERVAÇÕES: & $\begin{array}{l}\text { RESULTADO } \\
\text { DA VISITA }\end{array}$ & 1 - REALIZADA \\
\hline 1 & 1 & & & & & $\begin{array}{l}2 \text { - ADIADA } \\
3 \text { - MORADOR }\end{array}$ \\
\hline 2 & 1 & & & & & AUSENTE \\
\hline 3 & 1 & & & & & 5- RECUSA PABCIAL \\
\hline 4 & 1 & & & & & $\begin{array}{l}6 \text { - IMPOSSIBILITADO } \\
\text { DE RESPONDER }\end{array}$ \\
\hline 5 & 1 & & & & & $\begin{array}{l}7 \text { - OUTROS, } \\
\text { ESPECIF.: }\end{array}$ \\
\hline 6 & 1 & & & & & \\
\hline
\end{tabular}

Obs.:

B 01. RESULTADO DAS VISITAS:
B 02. $\mathrm{N}^{\circ}$. DE VISITAS:

B 04. DATA DA ENTREVISTA: 


\section{IDENTIFICAÇÃO:}

\section{B 05- DATA DE NASCIMENTO:}

$-1-1$

B 06-SEXO: 1 -MASCULINO 2 -FEMININO 1

\begin{tabular}{|c|c|c|c|c|c|c|}
\hline \multicolumn{3}{|c|}{ B 07- QUAL A SUA COR OU RAÇA? } & \multicolumn{3}{|c|}{ (LER AS ALTERNATIVAS) } & \\
\hline $\begin{array}{c}1- \\
\text { BRANCA }\end{array}$ & $\begin{array}{c}2- \\
\text { PRETA }\end{array}$ & $\begin{array}{c}3- \\
\text { AMARELA }\end{array}$ & $\begin{array}{c}4 \text { - } \\
\text { PARDA/MORENA }\end{array}$ & $\begin{array}{c}5 \text { - } \\
\text { INDÍGENA }\end{array}$ & $\begin{array}{c}9- \\
\text { NS/NR }\end{array}$ & \\
\hline
\end{tabular}

\section{SAÚDE - PERGUNTAS REFERENTES AOS ÚLTIMOS 12 MESES}

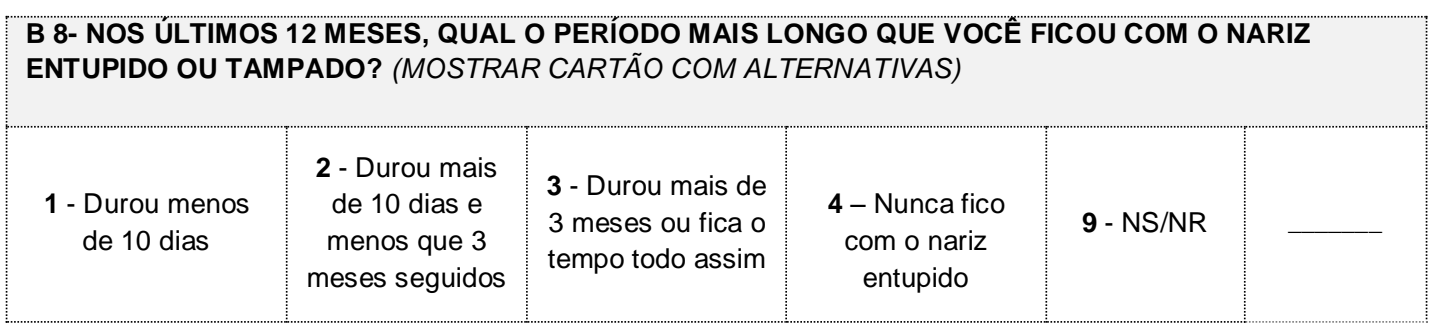

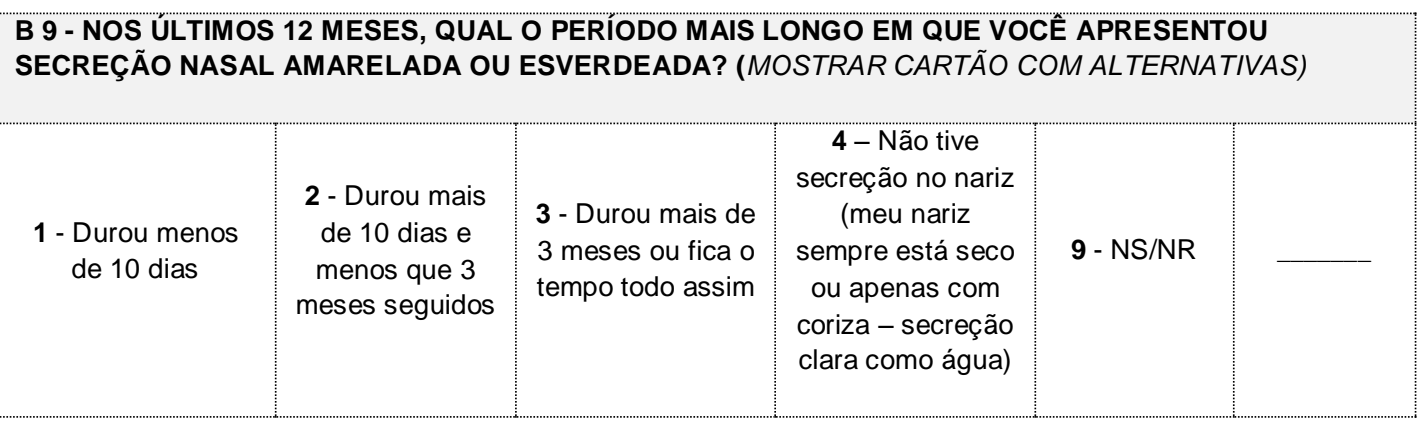

\begin{tabular}{|c|c|c|c|}
\hline $\begin{array}{l}\text { B } 10-\text { NOS ÚLTIMOS } 12 \text { MESES, VOCÊ TEVE } \\
\text { DIFICULDADE EM SENTIR CHEIRO NO PERÍODO EM QUE }\end{array}$ & $1-$ & 2 - & 9 - \\
\hline $\begin{array}{l}\text { ESTAVA COM_ } \\
\text { NARIZ ENTUPIDO)? (COMPLETAR COM A ALTERNATIVA } \\
\text { DE DURAÇÃO MAIS LONGA ENTRE AS QUESTÕES } 8 \text { OU } \\
\text { 9) }\end{array}$ & SIM & NÃO & NS/NR \\
\hline
\end{tabular}

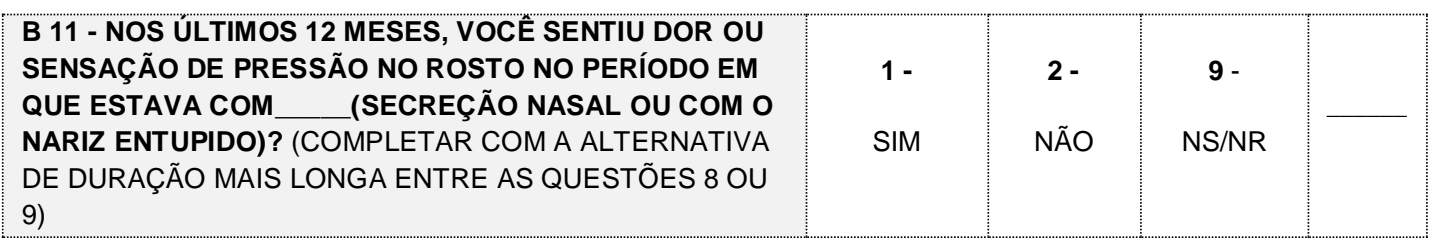


B 12 - NOS ÚLTIMOS 12 MESES, QUANTAS VEZES VOCÊ UTILIZOU ANTIBIÓTICOS (COMO AMOXICILINA, LEVOFLOXACINA, AZITROMICINA, CEFALEXINA - ver lista) APENAS PARA DOENÇAS NASAIS (SINUSITE, RINITE, GRIPE, RESFRIADO): SE RESPONDER QUE NÃO UTILIZOU NENHUMA VEZ, PULE PARA B14.

$99-\mathrm{NS} / \mathrm{NR}$

Se 00 , pular para questão 14

\begin{tabular}{|c|c|c|c|c|c|c|c|}
\hline B 13 - GERALMENTE ESTE & \multirow[t]{2}{*}{3 dias } & \multirow[t]{2}{*}{7 dias } & \multirow{2}{*}{$\begin{array}{c}10 \\
\text { dias }\end{array}$} & \multirow{2}{*}{$\begin{array}{c}14 \\
\text { dias }\end{array}$} & \multirow{2}{*}{$\begin{array}{c}21 \\
\text { dias }\end{array}$} & \multirow{2}{*}{$\begin{array}{c}28 \\
\text { dias } \\
\text { ou } \\
\text { mais }\end{array}$} & \multirow[t]{2}{*}{ NS/NR } \\
\hline MEDICAMENTO FOI & & & & & & & \\
\hline & 1 & 2 & 3 & 4 & 5 & 6 & 9 \\
\hline
\end{tabular}

B 14 - NOS ÚLTIMOS 12 MESES, QUANDO VOCÊ ENTROU EM CONTATO COM PÓ, MOFO, PÉLOS DE ANIMAIS, PÓLEN E NÃO ESTAVA GRIPADO OU RESFRIADO, VOCÊ APRESENTOU ALGUM DESTES SINTOMAS? SE RESPONDER NÃO PARA TODOS OS SINTOMA, PULE PARA B17

\begin{tabular}{|c|c|c|c|}
\hline & SIM & NÃO & NS/NR \\
\hline $\begin{array}{l}\text { CORIZA (SECREÇÄO NASAL CLARA COMO } \\
\text { ÁGUA) }\end{array}$ & 1 & 2 & 9 \\
\hline COCEIRA NO NARIZ & 1 & 2 & 9 \\
\hline COCEIRA NOS OLHOS & 1 & 2 & 9 \\
\hline $\begin{array}{l}\text { ESPIRROS (GERALMENTE VÄRIOS EM } \\
\text { SEQUENCIA) }\end{array}$ & 1 & 2 & 9 \\
\hline OBSTRUÇÃO NASAL / NARIZ ENTUPIDO & 1 & 2 & 9 \\
\hline
\end{tabular}

B 15 - NOS ÚLTIMOS 12 MESES, QUANDO VOCÊ ENTROU EM CONTATO COM IRRITANTES NASAIS (PÓ, MOFO, PÊLOS DE ANIMAIS, PÓLEN) E NÃO ESTAVA GRIPADO OU RESFRIADO, POR QUANTO TEMPO PERSISTIRAM ESTES SINTOMAS (CORIZA, COCEIRA, ESPIRROS, OBSTRUÇÃO)?

1 - MENOS DE 4 DIAS NA SEMANA OU MENOS DE 4 SEMANAS CONSECUTIVAS

2 - MAIS DE 4 DIAS POR SEMANA E MAIS DE 4 SEMANAS CONSECUTIVAS

$2-N S / N R$ 


\begin{tabular}{|c|c|c|c|c|}
\hline & SIM & NÃO & NS/NR & \\
\hline $\begin{array}{l}\text { ESTES SINTOMAS APARECEM MAS NÃO } \\
\text { INCOMODAM MUITO / SÃO SINTOMAS } \\
\text { LEVES E NÃO O MOTIVAM A PASSAR EM } \\
\text { CONSULTA MÉDICA }\end{array}$ & $\begin{array}{c}1 \\
\text { (INCOMODAM) }\end{array}$ & $\begin{array}{c}2 \\
\text { (NÃO } \\
\text { INCOMODAM) }\end{array}$ & 9 & \\
\hline PERTURBAM O SONO? & 1 & 2 & 9 & \\
\hline $\begin{array}{l}\text { ATRAPALHAM AS ATIVIDADES DIÁRIAS, O } \\
\text { LAZER E ESPORTES }\end{array}$ & 1 & 2 & 9 & \\
\hline ATRAPALHAM O TRABALHO OU ESTUDO & 1 & 2 & 9 & \\
\hline
\end{tabular}

B 17- VOCÊ TRABALHA EM LOCAL COM MUITO PÓ?

$\left.\begin{array}{c|c|c}\mathbf{1 -} & \mathbf{2 -} & \mathbf{9 -} \\ \mathrm{SIM} & \mathrm{NÃO} & \mathrm{NS} / \mathrm{NR}\end{array}\right]$

B 18- VOCÊ SE EXPÕE A AR CONDICIONADO FREQUENTEMENTE? (+ 3 dias / semana por mais de 4 horas / $1-\quad 2-\quad 9-$ dia)

SIM NÃO NS/NR

B 19- VOCÊ TRABALHA EXPOSTO A PRODUTOS QUÍMICOS?

$1-$
$\mathrm{IM}$$\left[\begin{array}{c|c}2- & 9- \\ \mathrm{NATO} & \mathrm{NS} / \mathrm{NR}\end{array}\right]$

$\left.\begin{array}{|l|l|l|l|l}\hline \text { B } 20-\text { VOCÊ CONVIVE EM AMBIENTE COM MOFO / } & 1- & 2- & 9- \\ \text { UMIDADE? } & \text { SIM } & \text { NÃO } & \text { NS/NR }\end{array}\right]$

\begin{tabular}{|c|c|c|}
\hline \multicolumn{3}{|c|}{ B 21- FUMA ATUALMENTE? } \\
\hline \multirow[t]{2}{*}{1 - SIM } & QUANTOS CIGARROS POR DIA? & \\
\hline & $\begin{array}{l}\text { HA QUANTO TEMPO FUMA? ANOTAR EM } \\
\text { ANOS } \\
\text { (tempo inferior a } 1 \text { ANO - anotar 00) }\end{array}$ & anos \\
\hline \multicolumn{3}{|c|}{$\begin{array}{l}2 \text { - NÄO, NUNCA } \\
\text { FUMOU }\end{array}$} \\
\hline $\begin{array}{l}\text { 3-NAO, EX- } \\
\text { FUMANTE }\end{array}$ & $\begin{array}{l}\text { HÁ QUANTO TEMPO PAROU DE FUMAR? } \\
\text { ANOTAR EM ANOS (tempo inferior a } 1 \\
\text { ANO-anotar 00) }\end{array}$ & _anos \\
\hline
\end{tabular}




\begin{tabular}{|c|c|c|c|}
\hline & SIM & NÂO & NS/NR \\
\hline RINITE & 1 & 2 & 9 \\
\hline ASMA OU CHIADO NO PEITO & 1 & 2 & 9 \\
\hline SINUSITE & 1 & $\begin{array}{c}2 \\
\text { (Pule para } \\
\text { questão } \\
\text { 23) }\end{array}$ & $\begin{array}{c}9 \\
\text { (Pule para } \\
\text { questão } \\
\text { 23) }\end{array}$ \\
\hline $\begin{array}{l}\text { B 22B- O MÉDICO DISSE SE A SINUSITE É } \\
\text { AGUDA OU CRÕNICA? }\end{array}$ & 1 - AGUDA & $\begin{array}{c}2- \\
\text { CRÔNICA }\end{array}$ & $9-N S / N R$ \\
\hline
\end{tabular}

\begin{tabular}{|c|c|c|c|}
\hline $\begin{array}{l}\text { B 23A- VOCÉ JA PASSOU EM CONSULTA COM } \\
\text { OTORRINOLARINGOLOGISTA (MÉDICO ESPECIALISTA } \\
\text { EM NARIZ, OUVIDO E GARGANTA)? }\end{array}$ & 1 - SIM & $\begin{array}{l}2-\mathrm{NAOO} \\
\text { (Encerrar } \\
\text { questionário) }\end{array}$ & $\begin{array}{l}9- \\
\text { NS/NR }\end{array}$ \\
\hline
\end{tabular}

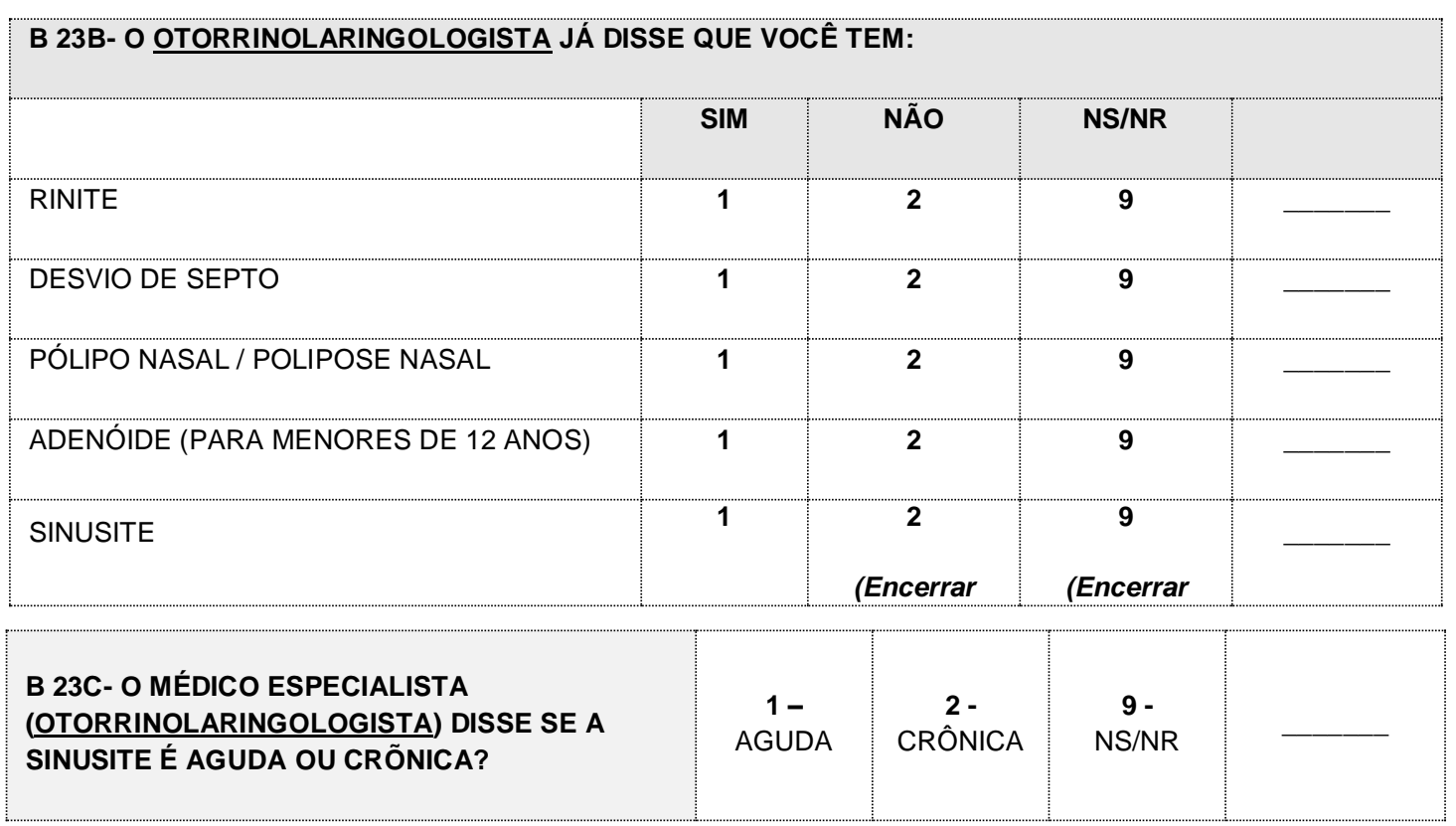



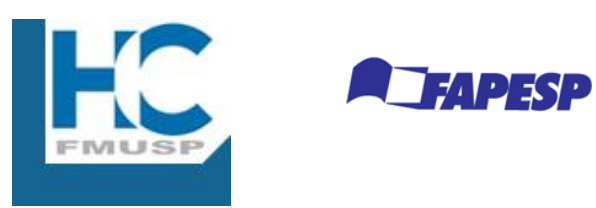

Distrito/Setor: 1

ID:

Nome do entrevistado:

\title{
DOMICÍlIO
}

BLOCO C

\begin{abstract}
PREENCHER UM BLOCO PARA CADA FAMÍLIA
\end{abstract}
(SOMENTE PODERÁ SER RESPONDIDO POR PESSOA MAIOR DE 18 ANOS)

C 01- QUANTAS PESSOAS HABITAM ESTA CASA?

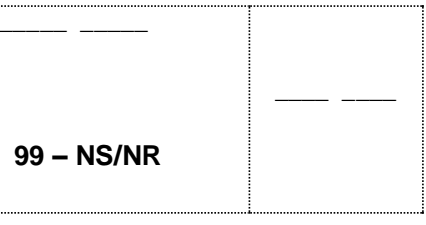

C 02- QUAL O NÚMERO DE CÔMODOS UTILIZADOS COMO DORMITÓRIO?

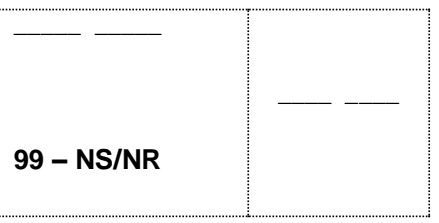

C 03- SOBRE O CHEFE DA FAMÍLIA - ATÉ QUE ANO DA ESCOLA COMPLETOU?

01 - NUNCA FREQUENTOU, NAO SABE LER E 07 - CURSOS TECNICOS DE NIVEL MÉDIO ESCREVER INCOMPLETOS

02 - NUNCA FREQUENTOU, MAS SABE LER E ESCREVER

08 - CURSOS TÉCNICOS DE NÍVEL MÉDIO

03 - ALFABETIZAÇÃO DE ADULTOS COMPLETOS

4 _ ANO OU SÉRIE (DE 1 A 4) DO 1 GRAU OU PRIMÁRIO

09 - CURSO SUPERIOR INCOMPLETO

5 ANO OU SÉRIE (DE 5 A 8) DO 1ํ GRAU OU GINÁSIO

6 _ ANO OU SÉRIE (DE 1 A 3) DO 2 GRAU OU 99 - NS/NR COLEGIAL

10 - CURSO SUPERIOR COMPLETO

11 - PÓS GRADUAÇÃO COMPLETA 


\begin{tabular}{|c|c|c|c|c|c|c|c|}
\hline $\begin{array}{l}\text { C 04- QUAL A } \\
\text { RENDA } \\
\text { MENSAL DO } \\
\text { CHEFE DE } \\
\text { FAMÍLIA? } \\
\text { (EM SALÁRIOS } \\
\text { MÍNIMOS) (R\$) }\end{array}$ & $\begin{array}{c}\text { Não } \\
\text { tem } \\
\text { renda }\end{array}$ & $\begin{array}{l}\text { Até } 1 \\
\text { salário } \\
\text { (Até } \\
510,00)\end{array}$ & $\begin{array}{c}1 \text { a } 3 \\
(511,00 \\
a \\
1.530,00)\end{array}$ & $\begin{array}{c}3 \text { a } 5 \\
(1.531,00 \\
\text { a } \\
2.550,00)\end{array}$ & $\begin{array}{c}5 \text { a } 10 \\
(2.551,00 \\
a \\
5.100,00)\end{array}$ & $\begin{array}{c}>10 \\
\text { (Acima } \\
\text { de } \\
5.101,00)\end{array}$ & $\mathrm{NS} / \mathrm{NR}$ \\
\hline \multicolumn{5}{|c|}{ C 05 - ALGUÉM FUMA NA SUA CASA? } & $\begin{array}{l}\text { 1- } \\
\text { SIM }\end{array}$ & $\begin{array}{c}2- \\
\text { NÃO }\end{array}$ & $\begin{array}{c}9- \\
\text { NS/NR }\end{array}$ \\
\hline
\end{tabular}


REFERÊNCIAS 


\section{REFERÊNCIAS}

1. Bhattacharyya N. Contemporary assessment of the disease burden of sinusitis. American Journal of Rhinology \& Allergy. 2009;23(4).

2. Anand VK. Epidemiology and economic impact of rhinosinusitis. Annals of Otology Rhinology and Laryngology. 2004;113(5).

3. Bhattacharyya N, Orlandi RR, Grebner J, Martinson M. Cost Burden of Chronic Rhinosinusitis: A Claims-Based Study. Otolaryngology-Head and Neck Surgery. 2011;144(3).

4. Ray NF, Baraniuk JN, Thamer M, Rinehart CS, Gergen PJ, Kaliner M, et al. Healthcare expenditures for sinusitis in 1996: contributions of asthma, rhinitis, and other airway disorders. J Allergy Clin Immunol. 1999;103(3 Pt 1):408-14.

5. Bhattacharyya N. Incremental Health Care Utilization and Expenditures for Chronic Rhinosinusitis in the United States. Annals of Otology Rhinology and Laryngology. 2011;120(7).

6. Bhattacharyya $\mathrm{N}$. The economic burden and symptom manifestations of chronic rhinosinusitis. Am J Rhinol. 2003;17(1):27-32.

7. Durr DG, Desrosiers MY, Dassa C. Impact of rhinosinusitis in health care delivery: the Quebec experience. J Otolaryngol. 2001;30(2):93-7.

8. Bezerra TF, Piccirillo JF, Fornazieri MA, de M Pilan RR, Abdo TR, de Rezende Pinna F, et al. Cross-Cultural Adaptation and Validation of SNOT-20 in Portuguese. Int J Otolaryngol. 2011;2011:306529.

9. Gliklich RE, Metson R. The health impact of chronic sinusitis in patients seeking otolaryngologic care. Otolaryngol Head Neck Surg. 1995;113(1):104-9.

10. Ware JE, Sherbourne CD. The MOS 36-item short-form health survey (SF-36). I. Conceptual framework and item selection. Med Care. 1992;30(6):473-83.

11. Hastan D, Fokkens WJ, Bachert C, Newson RB, Bislimovska J, Bockelbrink $A$, et al. Chronic rhinosinusitis in Europe - an underestimated disease. A GA(2)LEN study. Allergy. 2011;66(9). 
12. Fokkens W, Lund V, Mullol J, group EPPoRaNP. European position paper on rhinosinusitis and nasal polyps 2007. Rhinol Suppl. 2007(20):1136.

13. Schiller JS, Lucas JW, Ward BW, Peregoy JA. Summary health statistics for U.S. adults: National Health Interview Survey, 2010. Vital Health Stat 10. 2012(252):1-207.

14. Chen $\mathrm{Y}$, Dales $\mathrm{R}$, Lin $\mathrm{M}$. The epidemiology of chronic rhinosinusitis in Canadians. Laryngoscope. 2003;113(7).

15. Shashy RG, Moore EJ, Weaver A. Prevalence of the chronic sinusitis diagnosis in Olmsted County, Minnesota. Archives of OtolaryngologyHead \& Neck Surgery. 2004;130(3).

16. Fokkens WJ, Lund VJ, Mullol J, Bachert C, Alobid I, Baroody F, et al. European Position Paper on Rhinosinusitis and Nasal Polyps 2012. Rhinol Suppl. 2012(23):3 p preceding table of contents, 1-298.

17. Report of the Rhinosinusitis Task Force Committee Meeting. Alexandria, Virginia, August 17, 1996. Otolaryngol Head Neck Surg. 1997;117(3 Pt 2):S1-68.

18. Lanza DC, Kennedy DW. Adult rhinosinusitis defined. Otolaryngol Head Neck Surg. 1997;117(3 Pt 2):S1-7.

19. Benninger MS, Ferguson BJ, Hadley JA, Hamilos DL, Jacobs M, Kennedy DW, et al. Adult chronic rhinosinusitis: definitions, diagnosis, epidemiology, and pathophysiology. Otolaryngol Head Neck Surg. 2003;129(3 Suppl):S1-32.

20. Rosenfeld RM, Andes D, Bhattacharyya N, Cheung D, Eisenberg S, Ganiats TG, et al. Clinical practice guideline: Adult sinusitis. Otolaryngology-Head and Neck Surgery. 2007;137(3).

21. Almeida Filho N, Rouquayrol MZ. Introdução à Epidemiologia. 4a. ed. rev. e ampliada ed. Koogan G. Rio de Janeiro. 2006.

22. Van Cauwenberge P, Watelet JB. Epidemiology of chronic rhinosinusitis. Thorax. 2000;55 Suppl 2:S20-1.

23. Barros M. Inquéritos domiciliares de saúde: potencialidades e desafios. Rev Bras Epidemiol2008. p. 6-19.

24. Collins JG. Prevalence of selected chronic conditions: United States, 1990-1992. Vital Health Stat 10. 1997(194):1-89. 
25. Pleis JR, Lethbridge-Cejku M. Summary health statistics for U.S. adults: National Health Interview Survey, 2005. Vital Health Stat 10. 2006(232):1-153.

26. Pleis JR, Lethbridge-Cejku M. Summary health statistics for U.S. adults: National Health Interview Survey, 2006. Vital Health Stat 10. 2007(235):1-153.

27. Pleis JR, Lucas JW. Summary health statistics for U.S. adults: National Health Interview Survey, 2007. Vital Health Stat 10. 2009(240):1-159.

28. Pleis JR, Lucas JW, Ward BW. Summary health statistics for U.S. adults: National Health Interview Survey, 2008. Vital Health Stat 10. 2009(242):1-157.

29. Pleis JR, Ward BW, Lucas JW. Summary health statistics for U.S. adults: National Health Interview Survey, 2009. Vital Health Stat 10. 2010(249):1-207.

30. Kim YS, Kim NH, Seong SY, Kim KR, Lee G-B, Kim K-S. Prevalence and risk factors of chronic rhinosinusitis in Korea. American Journal of Rhinology \& Allergy. 2011;25(3).

31. Tomassen P, Newson RB, Hoffmans R, Lotvall J, Cardell LO, Gunnbjornsdottir M, et al. Reliability of EP3OS symptom criteria and nasal endoscopy in the assessment of chronic rhinosinusitis - a GA2LEN study. Allergy. 2011;66(4).

32. Diretrizes da Sociedade de Pneumologia e Tisiologia para o Manejo da Asma. J Bras Pneumol2012. p. S1-S46.

33. Jarvis D, Newson R, Lotvall J, Hastan D, Tomassen P, Keil T, et al. Asthma in adults and its association with chronic rhinosinusitis: The GA2LEN survey in Europe. Allergy. 2012;67(1).

34. Bhattacharyya N, Kepnes LJ. Additional disease burden from hay fever and sinusitis accompanying asthma. Ann Otol Rhinol Laryngol. 2009;118(9):651-5.

35. Dixon AE, Kaminsky DA, Holbrook JT, Wise RA, Shade DM, Irvin CG. Allergic rhinitis and sinusitis in asthma: differential effects on symptoms and pulmonary function. Chest. 2006;130(2):429-35.

36. Lin DC, Chandra RK, Tan BK, Zirkle W, Conley DB, Grammer LC, et al. Association between severity of asthma and degree of chronic rhinosinusitis. Am J Rhinol Allergy. 2011;25(4):205-8. 
37. Liou A, Grubb JR, Schechtman KB, Hamilos DL. Causative and contributive factors to asthma severity and patterns of medication use in patients seeking specialized asthma care. Chest. 2003;124(5):1781-8.

38. Lötvall J, Ekerljung L, Lundbäck B. Multi-symptom asthma is closely related to nasal blockage, rhinorrhea and symptoms of chronic rhinosinusitis-evidence from the West Sweden Asthma Study. Respir Res. 2010;11:163.

39. Bachert C, Claeys SE, Tomassen P, van Zele T, Zhang N. Rhinosinusitis and asthma: a link for asthma severity. Curr Allergy Asthma Rep. 2010;10(3):194-201.

40. Seybt MW, McMains KC, Kountakis SE. The prevalence and effect of asthma on adults with chronic rhinosinusitis. Ent-Ear Nose \& Throat Journal. 2007;86(7).

41. Bachert $C$, Patou J, Van Cauwenberge $P$. The role of sinus disease in asthma. Curr Opin Allergy Clin Immunol. 2006;6(1):29-36.

42. Bousquet J, Khaltaev N, Cruz AA, Denburg J, Fokkens WJ, Togias A, et al. Allergic Rhinitis and its Impact on Asthma (ARIA) 2008 update (in collaboration with the World Health Organization, GA(2)LEN and AllerGen). Allergy. 2008;63 Suppl 86:8-160.

43. III Consenso Brasileiro sobre Rinites - 2012. Braz J Otorhinolaryngol. 2012. p. S1-S51.

44. Bachert C, van Cauwenberge P, Olbrecht J, van Schoor J. Prevalence, classification and perception of allergic and nonallergic rhinitis in Belgium. Allergy. 2006;61(6):693-8.

45. Houser SM, Keen KJ. The role of allergy and smoking in chronic rhinosinusitis and polyposis. Laryngoscope. 2008;118(9):1521-7.

46. Tan BK, Zirkle W, Chandra RK, Lin D, Conley DB, Peters AT, et al. Atopic profile of patients failing medical therapy for chronic rhinosinusitis. Int Forum Allergy Rhinol. 2011;1(2):88-94.

47. Berrettini S, Carabelli A, Sellari-Franceschini S, Bruschini L, Abruzzese A, Quartieri F, et al. Perennial allergic rhinitis and chronic sinusitis: correlation with rhinologic risk factors. Allergy. 1999;54(3):242-8.

48. Sedaghat AR, Gray ST, Wilke CO, Caradonna DS. Risk factors for development of chronic rhinosinusitis in patients with allergic rhinitis. Int Forum Allergy Rhinol. 2012;2(5):370-5. 
49. Pant H, Ferguson BJ, Macardle PJ. The role of allergy in rhinosinusitis. Current Opinion in Otolaryngology \& Head and Neck Surgery. $2009 ; 17(3)$.

50. Lee S, Kundaria S, Ferguson BJ. Practical clinical management strategies for the allergic patient with chronic rhinosinusitis. Curr Opin Otolaryngol Head Neck Surg. 2012;20(3):179-87.

51. Lieu JE, Feinstein AR. Confirmations and surprises in the association of tobacco use with sinusitis. Arch Otolaryngol Head Neck Surg. 2000;126(8):940-6.

52. Cryer J, Schipor I, Perloff JR, Palmer JN. Evidence of bacterial biofilms in human chronic sinusitis. ORL J Otorhinolaryngol Relat Spec. 2004;66(3):155-8.

53. Bezerra TF, Padua FG, Gebrim EM, Saldiva PH, Voegels RL. Biofilms in chronic rhinosinusitis with nasal polyps. Otolaryngol Head Neck Surg. 2011;144(4):612-6.

54. Tamashiro E, Xiong G, Anselmo-Lima WT, Kreindler JL, Palmer JN, Cohen NA. Cigarette smoke exposure impairs respiratory epithelial ciliogenesis. Am J Rhinol Allergy. 2009;23(2):117-22.

55. Goldstein-Daruech N, Cope EK, Zhao KQ, Vukovic K, Kofonow JM, Doghramji L, et al. Tobacco smoke mediated induction of sinonasal microbial biofilms. PLoS One. 2011;6(1):e15700.

56. Kilty SJ, McDonald JT, Johnson S, Al-Mutairi D. Socioeconomic status: a disease modifier of chronic rhinosinusitis? Rhinology. 2011;49(5):533-7.

57. Instituto Brasileiro de Geografia e Estatística - IBGE [internet]. Sistema IBGE de Recuperação Automática - SIDRA. Banco de Dados Agregados. Disponível em: http://www.sidra.ibge.gov.br/.

58. Kish L. Survey sampling. New York: John Wiley \& Sons; 1965. 643 p.

59. Silva NNd. Amostragem probabilística: um curso introdutório. 2a. ed ed. São Paulo: Editora da Universidade de São Paulo; 2001. 125 p.

60. Instituto Brasileiro de Geografia e Estatística - IBGE [internet]. Sinopse por Setores. Disponível em: http://www.censo2010.ibge.gov.br /sinopseporsetores/?nivel=st. 
61. Instituto Brasileiro de Geografia e Estatística - IBGE [internet]. Censo Demográfico 2010. Disponível em; http://www.ibge.gov.br/home/ estatistica/populacao/censo2010/tabelas_pdf/Sao_paulo.pdf.

62. Ministério do Planejamento, Orçamento e Gestão (BR). Instituto Brasileiro de Geografia e Estatística - IBGE [internet]. Pesquisa de Orçamentos Familiares 2008-2009. Despesas, Rendimentos e Condições de Vida. Disponível em: http://www.ibge.gov.br /home/estatistica/populacao/condicaodevida/pof/2008_2009/POFpublica cao.pdf.

63. Pilan RR, Pinna FR, Bezerra TF, Mori RL, Padua FG, Bento RF, et al. Prevalence of chronic rhinosinusitis in Sao Paulo. Rhinology. 2012;50(2):129-38.

64. Bousquet J, Van Cauwenberge P, Khaltaev N, Group AW, Organization WH. Allergic rhinitis and its impact on asthma. J Allergy Clin Immunol. 2001;108(5 Suppl):S147-334.

65. Kaliner M. Treatment of sinusitis in the next millennium. Allergy Asthma Proc. 1998;19(4):181-4.

66. Karlsson G, Holmberg K. Does allergic rhinitis predispose to sinusitis? Acta Otolaryngol Suppl. 1994;515:26-8; Discussion 9.

67. Ministério da Saúde. Secretaria de Vigilância em Saúde. Secretaria de Gestão Estratégica e Participativa. Vigitel Brasil 2010: vigilância de fatores de risco e proteção para doenças crônicas por inquérito telefônico / Ministério da Saúde, Secretaria de Vigilância em Saúde, Secretaria de Gestão Estratégica e Participativa. - Brasília: Ministério da Saúde, 2011. Disponível em: http://bvsms.saude.gov.br /bvs/publicacoes/vigitel_2010.pdf. 
APÊNDICES 


\section{APÊNDICE 1}

\section{CARTA DA COMISSÃO DE ÉTICA}
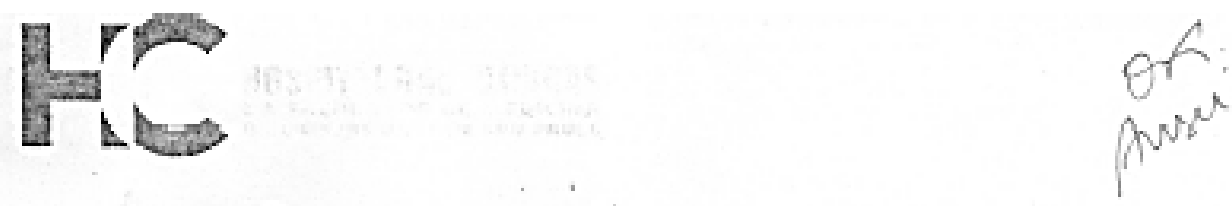

\section{APROVAÇĀO}

A Comissão de Ética para Anólise de Projetos de Pesquisa . CAPPesa da Diretoria Cínica do Hospital das Clinicas e da Foculdade de Medicina da Universidade $d \equiv 5$ o foulo em sesscao de 06/05/2009, APROVOU o Prolocolo de Pesquiso n ${ }^{\circ}$ 0399/09, intitu Goo: DETERMINAÇĀO OA PREVALENCIA DA RINOSSINUSITE ATRAVÉS DE INQUÉRITOS DOMICILIARES NA POPULAÇÃO DA CIDADE DE SĀO PAULO" apresentado pelo Cepartamento de OFTALMOLOGIA E OTORRINOLARINGOLOGIA, inclusive o Termo de Consentimento livte e Esclarecido.

Cabe do pesquisador elaboror e apresentor à CAPPesq, os relatórios parcia's i final sobre a pesquisa (Resoluçåo do Conselho Nacional de Saúde $n^{\circ} 196, d=10 \% 97 \%$ incisa lX.2, letra "c"].

Pesquisodor [a] Respor: t, : Prof. Dr. Richard Louis Voegels

Pesquisadoras Execu*a"*: Dra. Renata Ribeiro de Mendonça Pilan e Dra. Franeinl Grecco de Mello Pádua

Cinsera 07 ce maio de 2009

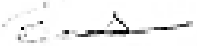

Prof. Dr. Eduardo Massad Presidenle da Comlssao de Ética para Análise de Projetos de Pesquisa 


\section{APÊNDICE 2}

\section{TERMO DE CONSENTIMENTO LIVRE E ESCLARECIDO}

HOSPITAL DAS CLÍNICAS DA FACULDADE DE MEDICINA

DA UNIVERSIDADE DE SÃO PAULO-HCFMUSP

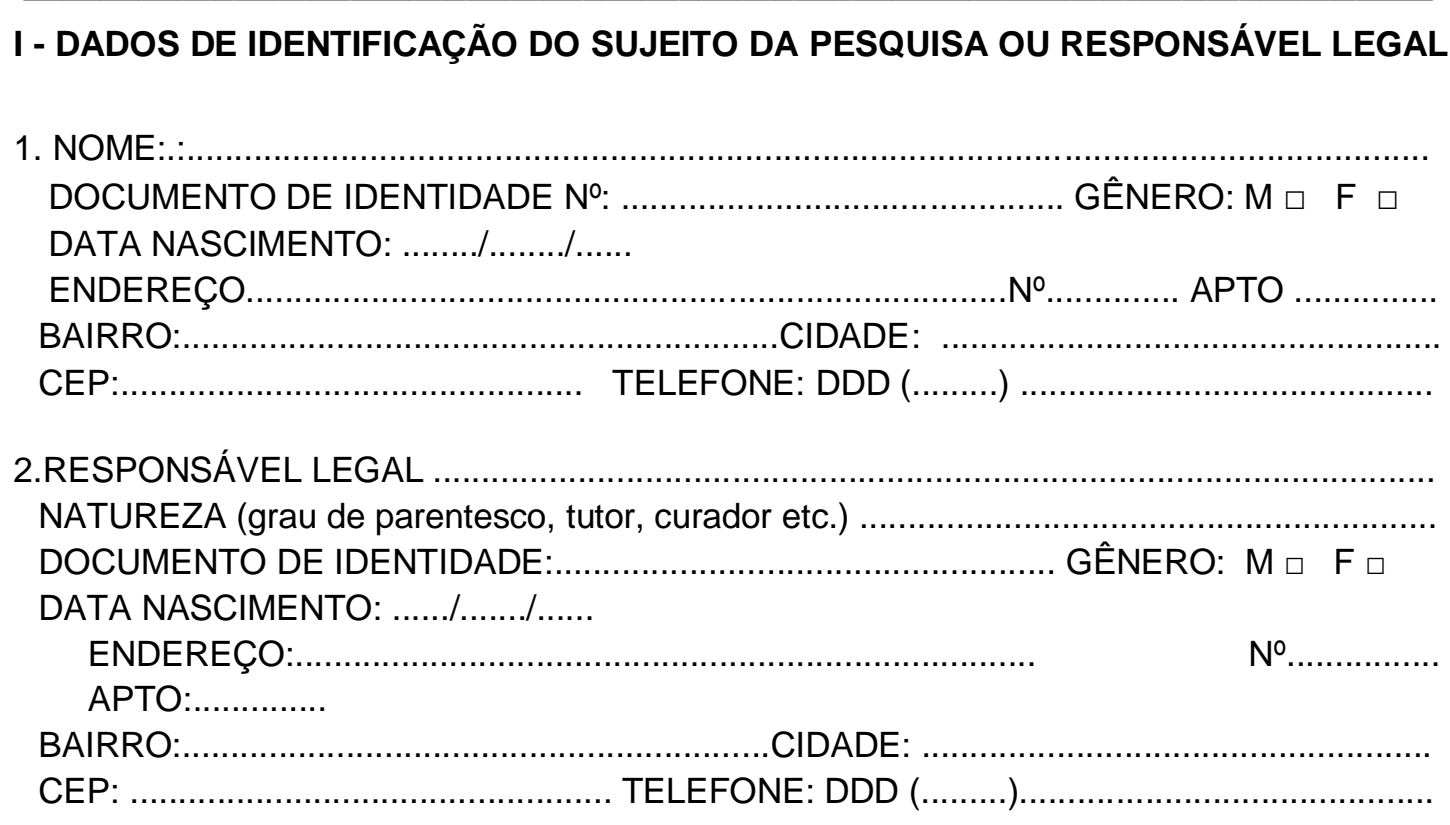

\section{I - DADOS SOBRE A PESQUISA CIENTÍFICA}

1. TÍTULO DO PROTOCOLO DE PESQUISA: Determinação da Prevalência da

Rinossinusite Através de Inquéritos Domiciliares na População da Cidade de São Paulo PESQUISADOR: Dr. Richard Louis Voegels

CARGO/FUNÇÃO: Professor Associado FMUSP

INSCRIÇÃO CONSELHO REGIONAL № SP-69967

UNIDADE DO HCFMUSP: Clínica Otorrinolaringológica - Departamento de

Otorrinolaringologia e Oftalmologia

2. AVALIAÇÃO DO RISCO DA PESQUISA:

$\begin{array}{llll}\text { SEM RISCO } & \text { RISCO MÍNIMO } \text { 凶 } & \text { RISCO MÉDIO } \\ \text { RISCO BAIXO } \square & \text { RISCO MAIOR } \square & \end{array}$

3. DURAÇÃO DA PESQUISA: 2 anos 


\section{III - REGISTRO DAS EXPLICAÇÕES DO PESQUISADOR AO PACIENTE OU SEU REPRESENTANTE LEGAL SOBRE A PESQUISA CONSIGNANDO:}

\section{Justificativa e os objetivos da pesquisa:}

\section{HOSPITAL DAS CLÍNICAS DA FACULDADE DE MEDICINA DA UNIVERSIDADE DE SÃO PAULO - HCFMUSP}

As doenças respiratórias são muito comuns na população e podem ser causada por vírus, bactérias ou fungos. Quando é causada por vírus, chamamos de "gripe" ou "resfriado". Sabemos que uma gripe ou resfriado mal tratado pode evoluir com infecção bacteriana e teremos a sinusite aguda. Tanto a gripe/resfriado quanto a sinusite aguda, quando não bem tratados, podem evoluir com complicações como a pneumonia, e podem ser graves especialmente em crianças e idosos. A sinusite também pode ser crônica, podendo também gerar alterações pulmonares nos pacientes, piorando a asma, a bronquite, e facilitando a pneumonia. De um modo geral, o paciente tem diminuição de sua qualidade de vida, muitas vezes tendo que faltar ao trabalho pelo mal estar causado.

Essas informações estão sendo fornecidas para sua participação voluntária neste estudo, que visa estimarmos qual o número de pessoas que têm doenças respiratórias na cidade de São Paulo e instituirmos uma política de prevenção assim como para elaboração de um tratamento mais adequado para todos os casos diagnosticados, reduzindo as possíveis complicações dessa doença.

Necessitamos apenas alguns minutos de sua atenção para responder ao questionário. As respostas serão analisadas pelo coordenador do estudo, e o seu nome será mantido em sigilo. As informações obtidas serão analisadas em conjunto com outros pacientes, não sendo divulgada a identificação de nenhum paciente. Caso você se sinta constrangido em responder alguma questão, você não é obrigado a respondê-la. É garantida a liberdade da retirada de consentimento a qualquer momento e deixar de participar do estudo. Não há despesas pessoais para o participante em qualquer fase do estudo e também não há compensação financeira relacionada à sua participação. No final do estudo, pacientes com sinusite diagnosticada, que necessitem de tratamento, serão encaminhados para tal. Caso o participante opte em não ter tratamento, ele não é obrigado a aceitá-lo.

Em qualquer etapa do estudo, você terá acesso aos profissionais responsáveis pela pesquisa para esclarecimento de eventuais dúvidas. O principal investigador é o Dr. Richard Louis Voegels que pode ser encontrado no endereço Av. Dr. Enéas de Carvalho Aguiar, 255 6을 andar - Departamento de Otorrinolaringologia - Telefone: 3069-6000. Se você tiver alguma consideração ou dúvida sobre a ética da pesquisa, entre em contato com o Comitê de Ética em Pesquisa (CEP) - Rua Ovídio Pires de Campos, 225 - 5 andar - tel: 3069-6442 ramais 16, 17, 18 ou 20, FAX: 3069-6442 ramal 26 - E-mail: cappesq@hcnet.usp.br

Acredito ter sido suficientemente informado a respeito das informações que li ou que foram lidas para mim, descrevendo o estudo "Determinação da Prevalência de Rinossinusite através de Inquéritos Domiciliares na População da Cidade de São Paulo". 
Eu discuti com o entrevistador responsável sobre a minha decisão em participar nesse estudo. Ficaram claros para mim quais são os propósitos do estudo, os procedimentos a serem realizados, seus desconfortos e riscos, as garantias de confidencialidade e de esclarecimentos permanentes. Ficou claro também que minha participação é isenta de despesas. Concordo voluntariamente em participar deste estudo e poderei retirar o meu consentimento a qualquer momento, antes ou durante o mesmo, sem penalidades ou prejuízo ou perda de qualquer benefício que eu possa ter adquirido.

São Paulo, .20

Assinatura do paciente/

Assinatura da testemunha

representante legal

Para casos de pacientes menores de 18 anos, analfabetos, semianalfabetos ou portadores de deficiência auditiva ou visual.

\section{(Somente para o responsável do projeto)}

Declaro que obtive de forma apropriada e voluntária o Consentimento Livre e Esclarecido deste paciente ou representante legal para a participação neste estudo.

\section{Assinatura do responsável pela pesquisa}

Data: $. / 20 \ldots . . .$. 